\title{
Adoption of Mobile Government Cloud from the Perspective of Public Sector
}

\author{
Yikai Liang $\mathbb{D}^{1},{ }^{1}$ Weijie Wang $\mathbb{D}^{1},{ }^{1}$ Kunxiang Dong $\left(\mathbb{D},{ }^{1}\right.$ Guijie Zhang $\mathbb{D}^{1},{ }^{1}$ and Guijie Qi $\mathbb{D}^{2}$ \\ ${ }^{1}$ School of Management Science and Engineering, Shandong University of Finance and Economics, Jinan 250014, China \\ ${ }^{2}$ College of Business, Shandong University (Weihai), Weihai 264209, China \\ Correspondence should be addressed to Guijie Qi; qiguijie@sdu.edu.cn
}

Received 14 August 2020; Revised 11 December 2020; Accepted 28 December 2020; Published 21 January 2021

Academic Editor: Juan C. Cano

Copyright (c) 2021 Yikai Liang et al. This is an open access article distributed under the Creative Commons Attribution License, which permits unrestricted use, distribution, and reproduction in any medium, provided the original work is properly cited.

Mobile cloud computing (MCC) has been widely used in every aspect of our society, bringing both advantages and challenges. However, the adoption of MCC technology is still at an early stage of implementation in the governments. To promote the adoption and diffusion of MCC in the government area, exploring the determinants and influence mechanisms of mobile cloud computing-based government ( $\mathrm{m}$-Gov cloud) adoption has become the focus in academic and industry. Based on the technologyorganization-environment framework and trust theory at the organizational level, an integrated model including the determinants on the adoption of $\mathrm{m}$-Gov cloud is proposed, and 93 survey samples from China are used to analyzed by partial least squares structural equation modeling (PLS-SEM). The results show that provider competence, organizational readiness, external pressure, and trust of $\mathrm{m}$-Gov cloud have significant effects on $\mathrm{m}$-Gov cloud adoption. Perceived benefit, perceived risk, and provider competence have significant effects on $\mathrm{m}$-Gov cloud trust. The $\mathrm{m}-\mathrm{Gov}$ cloud trust plays an indirect-only (full) mediation and a complementary (partial) mediation effect between perceived benefit, provider competence, and m-Gov cloud adoption, respectively, while perceived risk has no significant direct and indirect effect on $\mathrm{m}$-Gov cloud adoption. The findings provide a new research perspective and practice insights to promote the implementation of solutions based on the idea of mobile cloud computing.

\section{Introduction}

Cloud computing, disruptive innovation technology that extends existing IT capabilities and requirements $[1,2]$, provides flexible and on-demand computing resources [3-7], which has gained substantial attention in both academia and industry [8-12]. Recently, cloud computing paradigm direction is toward mobile with advances of mobile network and mobile devices [1]. Mobile cloud computing (MCC), an infrastructure, application, or process, where the data storage and processing migrated from smart mobile technologies to the distributed cloud servers [13], provides a platform for resource-constrained mobile devices to offload their tasks by cloud service providers (CSPs), mobile operators, and mobile vendors [6, 14]. MCC, with the characteristics of cloud computing and its own features such as mobility and real-time and wireless data transmission [15], has been used in a broad variety of fields $[16,17]$, e.g., mobile cloud storage services [3], healthcare system $[18,19]$, and educational use in higher education [13]. By investing in MCC, organizations could improve their capabilities without purchasing new hardware or software, reduce the initial installation and maintenance costs, and promote efficiency and green technology [7, 13].

Although perceptions of uncertainty have emerged regarding the use of MCC, e.g., privacy and security issues [17], few ones doubt MCC will continue to rise. In the context of public sectors, in order to improve the efficiency of administration and the quality of public service [20,21], many governments all over the world have introduced MCC to deliver mobile government information services anywhere and anytime to citizens, businesses, governments, and employees $[17,22]$. In order to promote the adoption and diffusion of MCC in the government context, therefore, it is 
of great practical significance to explorer the determinants and mechanisms of mobile cloud computing-based government ( $\mathrm{m}$-Gov cloud) adoption [12].

Previous studies of $\mathrm{m}$-Gov cloud focus on the benefits and challenges analysis $[20,21]$ and architecture and framework of design, implementation, and deployment $[23,24]$. However, few studies have explored the determinants and mechanisms of $\mathrm{m}-\mathrm{Gov}$ cloud adoption from innovation adoption perspectives. Understanding the determinants and mechanisms can reveal and acquire insight into challenges associated with this emerging trend. In order to fill this gap, based on technology-organization-environment (TOE) framework and trust theory, combined with two-factor theory (TFT) and institutional theory (INT), this study develops an integrated model including the determinants on $\mathrm{m}$-Gov cloud adoption from government agencies perspective. This integrated model makes up for the inadequate explanation of the organizational behavior adopted by a single model and reveals the determinants and intrinsic mechanisms of IT adoption by government agencies under the m-Gov cloud's background. This study has answered the issue of "what," i.e., the determinants that influence the government's adoption of $\mathrm{m}$-Gov cloud, and explained the issue of "how," i.e., the influence mechanisms of adopting m-Gov cloud. The study's findings not only enriched empirical research on the adoption of m-Gov cloud at the organizational level, especially in government agencies, but also helped to understand the emerging phenomenon of $\mathrm{m}$-Gov cloud and provided guidance to policy-makers and marketing strategies to MCC providers.

\section{Literature Review and Theoretical Background}

2.1. Definition and Adoption of Mobile Cloud Computing and Mobile Government Cloud. As NIST definition, cloud computing is a model for enabling convenient, on-demand network access to a shared pool of configurable computing resources (e.g., networks, servers, storage, applications, and services) that can be rapidly provisioned and released with minimal management effort or service provider interaction $[6,7,12,25]$. As the definition of Shin and Huh [1], MCC is the technical and functional supporting about processing of mobile cloud services. The supporting components for platform services are server, storage, network, and controlling device. These services are operated by a cloud service provider (CSP) $[6,14]$, which typically delivers its services using three service models: Infrastructure-as-a-service (IaaS), platform-as-a-service (PaaS), or software-as-a-service (SaaS) $[1,7,10,12,17,26]$. It is thus clear that MCC provides cloud computing resources to mobile devices with limited resources, which allows for the development and execution of robust applications [27].

MCC has benefits in decreasing the less delay, cost, and power consumption and increasing the more privacy, mobility, and scalability compared to other mobile architectures $[14,28]$. Therefore, MCC has been applied in various domains, including mobile learning, commerce, government, health/wellness, education, and social media [29].
MCC adoption is considered one of a hot topic in recent research $[3,13]$. However, as shown in Table 1, the number of empirical studies investigating the factors which influence the MCC adoption decisions at government agencies is very limited.

M-Gov cloud is a new e-Gov paradigm that incorporates MCC's essential characteristics (i.e., mobility, on-demand self-service, broad network access, resource pooling, rapid elasticity, and measured service) [31]. The technology provides a high level of integrated e-Gov service to many users by bringing web service of each government organization distributed into virtualized mobile service space by using mobile cloud computing [24]. Introducing the MCC to e-Gov has various benefits. For example, Mitrovic et al. used the Information Management Body of Knowledge (IMBOK) to understand the way of achieving the CC-based m-government benefits and used the access-adoption-appropriation model to understand the way the citizens can obtain benefits for these technologies and concepts [20]. Due to these benefits, various m-Gov based MCCs have been presented in previous studies. For example, Simić et al. developed a model for e-government mobile services in the cloud computing environment in South Africa [21]. This proposed infrastructure suggests that e-Gov portal and web service for integration with mobile devices are installed on virtual machines in the cloud computing infrastructure. Kim et al. designed MCC e-Gov using Korea central government cloud cluster by using WebSockets API newly added to HTML5, to improve the real-time performance of mobile applications [24]. Kharma et al. proposed a 3-tier mediation framework based on private cloud computing for adapting the content of M-Gov services using RBAC and derive unique key per transaction (DUKPT) [23].

2.2. IT Adoption Models. Information Technology (IT) adoption has been one of the hot topics in IS research [32]. There are several popular theoretical models for exploring factors of IT adoption at different levels (e.g., individual, group, and organization) and revealing the process of innovation adoption (e.g., preadoption, adoption decision, and postadoption).

As our research aims to explore the determinants of $\mathrm{m}$-Gov cloud adoption from the perspective of government agencies, we first review the prominent theoretical theories and models used for IT adoption at the organizational level [32], e.g., TOE framework, trust theory, two-factor theory, and institutional theory.

2.2.1. TOE Framework. Tornatzky and Fleischer proposed TOE framework for analyzing the technology diffusion process at the organization level, arguing that innovation diffusion is not only affected by technology's own characteristics but also by internal organization and external environment factors [33]. Therefore, decision-makers should consider these three dimensions' determinants to make a decision [32]. As TOE framework is highly adaptable and broadly applicable [34], for different innovation technologies (the object of adoption) and different organizations (the 
TABLE 1: Empirical studies on MCC adoption.

\begin{tabular}{lcccc}
\hline References & Theory & $\begin{array}{c}\text { Country } \\
\text { (context) }\end{array}$ & Level & Method \\
\hline & & & & \\
Almaiah \& & Integrated & & \\
Al- & Saudi Arabia & Individual & Questionnaire \\
Khasawneh & model & (education) & & academic \\
{$[27]$} & & & & staff) \& SEM
\end{tabular}

$\begin{array}{ll}\begin{array}{c}\text { Independent } \\ \text { variable }\end{array} & \begin{array}{c}\text { Dependent } \\ \text { variable }\end{array} \\ & \\ \text { Puality of service, } & \\ \text { PU, perceived } & \\ \text { privacy, trust, } & \begin{array}{c}\text { Intention to } \\ \text { adopt MCC }\end{array} \\ \text { and PEOU } & \end{array}$

Key findings

Quality of service,

$\mathrm{PU}, \mathrm{PEOU}$, relative

advantage, and trust.

Security and privacy

concerns still

prevent MCC

adoption in Saudi universities.

The students' information management (i.e.,

\begin{tabular}{|c|c|c|c|c|c|c|}
\hline Arpaci [13] & TRA & $\begin{array}{c}\text { Turkey } \\
\text { (education) }\end{array}$ & Individual & $\begin{array}{c}\text { Survey (308 } \\
\text { undergraduate } \\
\text { student) \& SEM } \\
\text { and machine } \\
\text { learning }\end{array}$ & $\begin{array}{c}\text { Information } \\
\text { retrieval, storage, } \\
\text { sharing, application, } \\
\text { and attitude }\end{array}$ & $\begin{array}{l}\text { Behavioral } \\
\text { intentions }\end{array}$ \\
\hline
\end{tabular}
retrieve, store, share, and apply) practices significantly affect their attitudes, which significantly affects behavioral intentions to use MCC.

\begin{tabular}{|c|c|c|c|c|c|c|}
\hline $\begin{array}{l}\text { Carreiro \& } \\
\text { Oliveira [28] }\end{array}$ & DOI & $\begin{array}{l}\text { Portugal } \\
\text { (firm) }\end{array}$ & Organization & $\begin{array}{l}\text { Survey (154 } \\
\text { firms) \& PLS }\end{array}$ & $\begin{array}{l}\text { Vision, intellectual } \\
\text { stimulation, } \\
\text { supportive } \\
\text { leadership, } \\
\text { supportive } \\
\text { leadership, and } \\
\text { personal recognition }\end{array}$ & $\begin{array}{l}\text { Intention, } \\
\text { adoption, and } \\
\text { routinization }\end{array}$ \\
\hline
\end{tabular}

Leaders' vision, combined with the capacity to consider others' feelings and recognize others' personal needs, is strongly related to MCC adoption.

Attitude, PEOU,
PU, social influence,

Attitude to use, PEOU, PU, accessibility of MCC, social influence, personal

\begin{tabular}{|c|c|c|c|c|}
\hline $\begin{array}{l}\text { Abdulfattah } \\
{[30]}\end{array}$ & TAM & $\begin{array}{c}\text { Saudi Arabia } \\
\text { (education) }\end{array}$ & Individual & $\begin{array}{c}\text { Survey (163 } \\
\text { students) \& } \\
\text { ANOVA }\end{array}$ \\
\hline
\end{tabular}

innovativeness, and perceived privacy and security concerns accessibility, individual characteristics, perceived privacy, and security are important determinants of intention to use MCC.

intention to use MCC MCC.

Perceived uncertainty and its antecedents (perceived information

Survey (263

Kim \& Kim Agency $\quad$ Korea Individual users) \& regression analysis asymmetry, fears of service provider opportunism, and information privacy \& security concerns), and three motivators (trust, convenience, and social presence)
Trust and convenience are motivators, and perceived Intention to utilize MCC and actual utilization uncertainty is a mitigator for adopting MCC services. 
TABLE 1: Continued.

\begin{tabular}{|c|c|c|c|c|c|c|c|}
\hline References & Theory & $\begin{array}{c}\text { Country } \\
\text { (context) }\end{array}$ & Level & Method & $\begin{array}{c}\text { Independent } \\
\text { variable }\end{array}$ & $\begin{array}{c}\text { Dependent } \\
\text { variable }\end{array}$ & Key findings \\
\hline $\begin{array}{l}\text { Amin et al. } \\
{[19]}\end{array}$ & UTAUT & $\begin{array}{c}\text { Malaysia, } \\
\text { Pakistan, and } \\
\text { Saudi Arabia } \\
\text { (healthcare) }\end{array}$ & Individual & $\begin{array}{c}\text { Survey (147 } \\
\text { healthcare } \\
\text { professionals) \& } \\
\text { regression } \\
\text { analysis }\end{array}$ & $\begin{array}{l}\text { Performance } \\
\text { expectancy, effort } \\
\text { expectancy, } \\
\text { facilitating } \\
\text { conditions, and } \\
\text { social influence }\end{array}$ & $\begin{array}{l}\text { Behavioral } \\
\text { intention }\end{array}$ & $\begin{array}{c}\text { Social influence is } \\
\text { the least predictor in } \\
\text { determining the } \\
\text { user's behavioral } \\
\text { intentions toward } \\
\text { using mobile cloud- } \\
\text { based healthcare } \\
\text { services. }\end{array}$ \\
\hline Arpaci [3] & TAM & $\begin{array}{c}\text { Turkey } \\
\text { (education) }\end{array}$ & Individual & $\begin{array}{c}\text { Survey (262 } \\
\text { undergraduate } \\
\text { students) \& SEM }\end{array}$ & $\begin{array}{l}\text { PEOU, perceived } \\
\text { ubiquity, PU, } \\
\text { perceived security, } \\
\text { perceived privacy, } \\
\text { trust, subjective } \\
\text { norm, and attitude }\end{array}$ & $\begin{array}{l}\text { Intention to } \\
\text { use mobile } \\
\text { cloud storage } \\
\text { services }\end{array}$ & $\begin{array}{c}\text { PU, subjective } \\
\text { norm, and trust have } \\
\text { significantly positive } \\
\text { effects on the } \\
\text { attitude, which is a } \\
\text { significant predictor } \\
\text { of behavioral } \\
\text { intentions. }\end{array}$ \\
\hline $\begin{array}{l}\text { Park \& Kim } \\
{[16]}\end{array}$ & TAM & $\begin{array}{c}\text { South Korea } \\
\text { (education) }\end{array}$ & Individual & $\begin{array}{c}\text { Interviews (16 } \\
\text { students) and } \\
\text { survey (1099 } \\
\text { samples) \& SEM }\end{array}$ & $\begin{array}{c}\text { PU, attitude, } \\
\text { mobility, } \\
\text { connectedness, } \\
\text { security, service \& } \\
\text { system quality, and } \\
\text { satisfaction }\end{array}$ & $\begin{array}{l}\text { Intention to } \\
\text { use MCC } \\
\text { services }\end{array}$ & $\begin{array}{l}\text { User acceptance of } \\
\text { MCC services is } \\
\text { largely affected by } \\
\text { perceived mobility, } \\
\text { connectedness, } \\
\text { security, quality of } \\
\text { service and system, } \\
\text { and satisfaction. }\end{array}$ \\
\hline
\end{tabular}

Note: theory of reasoned action, TRA; diffusion of innovation, DOI; perceived usefulness, PU; perceived ease of use, PEOU.

subject of adoption), the specific components and the influence mechanisms of TOE vary widely. Therefore, TOE framework has widely been utilized in IT adoption studies at the organizational level [35], e.g., cloud computing $[2,6,10,36-40]$, hospital electronic signatures [41], and open government data [34].

Although TOE framework takes into account the internal and external factors of the organization, as well as technology characteristics for technology adoption, it is a generic taxonomy framework that only suggests different sources of influence without specifying variables of each $[10,34,37]$. Therefore, in order to enhance the proposed model's explanatory power and better explain IT adoption [32], many scholars have called for that TOE framework could be combined with other theories or constructs, e.g., TAM [2, 10], DOI [36], INT [37, 42], and risk [6].

Accordingly, in this study, we employ TOE as a basic taxonomy framework to guide a systematic analysis to identify and classify the factors from technology, organization, and environment dimensions. Meanwhile, we combine TOE framework with other theories, e.g., twofactor theory and institutional theory, to better explain $\mathrm{m}-\mathrm{Gov}$ cloud adoption.

2.2.2. Two-Factor Theory. Two-factor theory (TFT) of technology adoption adapted from Herzberg's two-factor theory of motivation [43] has emerged recently in IS research [44-46]. Cenfetelli and Schwarz drew on TFT to classify individual perceptions on technology into enablers (motivators and satisfiers) and inhibitors (demotivators and hygiene factors); note that enablers and inhibitors play critical roles in IT adoption [44]. In IS context, enablers refer to the perceived factors about the relevant system's design and function that motivate users to adopt IT, e.g., perceived usefulness, ease of use, performance, and compatibility $[10,47-50]$. Inhibitors are the sets of factors that hinder the use of the systems, e.g., privacy, security, and complexity $[5,7,10,11,35,44]$. Each of the two factors is not opposed to the other and has effects on individual intents as dual-factor constructs independently [46]. That is, an individual can have perceptions of both enablers and inhibitors simultaneously. Moreover, inhibitors can hinder adoption despite enablers' presence, while the absence of inhibitors may not promote the adoption [44]. Therefore, TFT is often used to analyze emerging technologies' two-side nature [44-46].

Adopting behavior toward $\mathrm{m}-\mathrm{Gov}$ cloud is a decision to simultaneously consider the advantages and disadvantages of m-Gov cloud technology [46]. Although extant models, e.g., technology acceptance model [51], unified theory of acceptance and use of technology [52], and diffusion of innovation [53], help us make substantial progress in understanding technology adoption, their focus has been primarily on adoption enablers $[44,46]$. Therefore, to better understand the agencies' adoption behavior toward m-Gov cloud, the two-factor theory explaining the dual roles of enablers and inhibitors about m-Gov cloud was selected to be relevant to this study. Specifically, in our study, the enablers and inhibitors gained by introducing MCC into government refer to expected benefits and expected risks, respectively. 
2.2.3. Institutional Theory. Institutional theory (INT) states that organizations exist not only within a given technological environment but also within a given institutional environment [32]. INT explains how the institutional environment affects the organization's behavior and believes that organizational behavior is constrained by the institutional environment in which it operates, rather than technological criteria [54]. Hence, an entirely independent rational decision does not exist [55]. In IS context, INT is widely used for IT adoption in organizations, e.g., cloud computing $[37,56]$, enterprise architecture [42], and government systems [54]. Although INT can effectively explain the impact of external environmental factors on adopting technological innovation in organizations, it is one sided when only considering the environmental context.

As government agencies are required to conform to the legitimacy set by institutions to a more considerable extent than private sectors [54], in this study, we use INT to identify external pressures and to enhance TOE for better explaining organizational behavior within $\mathrm{m}-\mathrm{Gov}$ cloud context $[32,35]$.

2.2.4. Trust Theory. Trust, the core prerequisite for establishing positive relations in various contexts, facilitates a win-win cooperation strategic relationship [39]. Trust is also a vital technology adoption determinant [57]. From the source of trust, trust can be divided into institution-based trust and trust in IT artifact. Institution-based trust is a set of institutional environments that give favorable conditions to ensure the confidence that the expected efforts can be achieved, including structural assurance and situational normality $[58,59]$. Trust in IT artifact is the confidence that a particular technology with the necessary characteristics can fulfill the user's expectations [60, 61]. From the formation and development of trust, trust can be divided into initial trust and knowledge-based trust [58]. The initial trust means that a decision depends on the trustors' judgments before they experience the trustees [47]. The experience-based trust is the trustors know the other party well enough to predict trustees' behavior in a situation [60]. No matter what kind of trust, it plays an essential role in establishing the cooperation relationship between trustor and trustee, especially in a mobile environment. In IS context, trust theory is widely used in the studies on different information technologies adoption (e.g., mobile banking, online shopping, mobile government, and cloud computing) at different levels (e.g., organization and individual) in different contexts (e.g., government, business, and individual) $[2,7,11$, $12,39,47,50,59,61,62]$.

In this study, besides technological, organizational, and environmental contexts, we also focus on trust because of its posited dominant impacts during the initial stage of $m-G o v$ cloud adoption intention formation [63].

2.2.5. Review of IT Adoption Theory. In IT adoption at the organizational level, a single perspective or theoretical model is not enough to effectively explain the mechanisms of organizational IT adoption. Therefore, to make use of different models in various situations to complement each other, some scholars advocate using an integrated IT adoption model to explore IT adoption [37]. Therefore, this study develops an integrated model based on the above IT adoption theory, which not only helps discover more comprehensive factors influencing from technological, organizational, and environmental contexts, but also makes up for the inadequacy of a single theory to explain IT adoption at the organizational level.

\section{Conceptual Model and Hypothesis}

As suggested by Arpaci et al. [32, 64], we need to consider technological, organizational, and environmental contexts, in order to explore organizational adoption of $\mathrm{m}$-Gov cloud comprehensively. Therefore, TOE framework is used as the taxonomy framework to classify the determinants from the three contexts. Given the TOE framework's shortcoming $[10,34,37]$, this framework should be enhanced by other models to better explain IT adoption [35]. Therefore, the two-factor theory and the institutional theory are used to specify variables of technological and environmental contexts. Specifically, in the technological context, the twofactor theory is used to explain the dual roles of enablers and inhibitors about $\mathrm{m}$-Gov cloud characteristics, i.e., expected benefit and expected risk. Besides, we also consider the characteristics of $\mathrm{m}$-Gov cloud provider (i.e., provider competence) as a determinant for $\mathrm{m}$-Gov cloud adoption because $\mathrm{m}$-Gov cloud has a dual nature of being an IT artifact and a service provided by a provider [57, 65]. In environmental context, INT is used to explain the external pressures primarily stemmed from superior organizations, upstream and downstream organizations, and citizens. Besides technological, organizational, and environmental contexts, this study also focuses on trust because of its posited dominant impacts during the initial stage of $\mathrm{m}-\mathrm{Gov}$ cloud adoption intention formation [63].

Relying on a synthesis of several theories, e.g., TOE framework, TFT, INT, and trust theory, we develop an integrated model as depicted in Figure 1. The model links the technological drivers to trust of $\mathrm{m}-\mathrm{Gov}$ cloud and further links trust of $\mathrm{m}$-Gov cloud, technological, organizational, and environmental drivers to government agencies' adoption of $\mathrm{m}$-Gov cloud, based on which a series of hypotheses are proposed in the next.

3.1. Technological Context. The technological context relates to the technologies available to an organization, critical to an organization's adoption of technology [33]. It focuses on how technology characteristics themselves can influence the adoption process [32]. M-Gov cloud service has a dual nature of being an IT artifact and a service provided by an organization $[57,65]$. Therefore, in technological context, we consider the technology characteristics of $\mathrm{m}$-Gov cloud, and the characteristics of providers, respectively, for $\mathrm{m}-\mathrm{Gov}$ cloud adoption. 


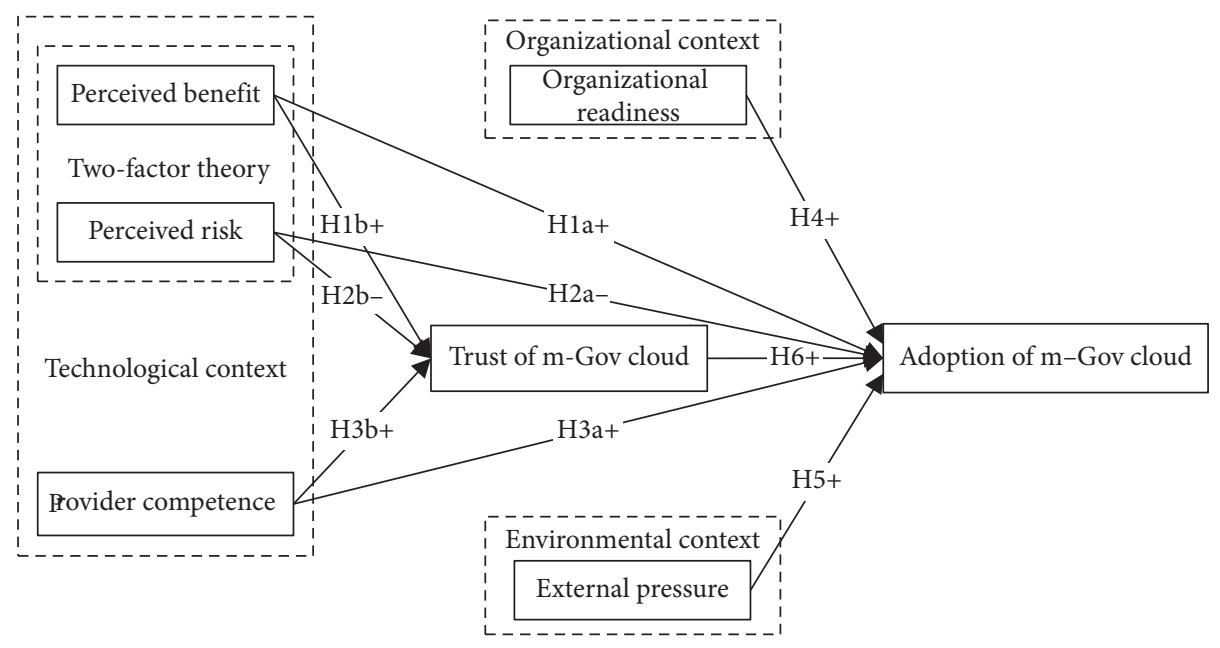

Figure 1: Research model.

3.1.1. Technology Characteristics of M-Gov Cloud. In the technological context, the characteristics of innovative technology have significant effects on the adoption decision $[38,66]$. The quantification of a technology's advantages or disadvantages may generate perceptions of possible benefits or risks that enable or inhibit the adoption process [44, 67]. When organizations consider the adoption decision, they have to face the trade-off between the perceived benefits and risks from the adoption of innovative technology [2, 34]. M-Gov cloud is a technological innovation and a service model innovation for governments [65]. It incorporates MCC into government services and then belongs to the type III innovation that means innovations imbed in the business's core technology [68]. While $\mathrm{m}-\mathrm{Gov}$ cloud brings corresponding benefits to government agencies, it also brings more uncertainties and risks $[2,39]$. Accordingly, the adoption of $\mathrm{m}$-Gov cloud needs to consider both the enablers and inhibitors. Based on the two-factor theory $[45,46]$, the agencies' perceptions of technology characteristics of $\mathrm{m}$-Gov cloud can be operationalized as two perceived factors, i.e., perceived benefit and perceived risk.

Perceived benefit refers to the extent to which an IT innovation can bring anticipated advantages to an organization, which is the enabler for technology adoption $[34,38,44]$. Compared with traditional IT, the technological advantages of MCC, e.g., cost-saving, mobility, connectedness, system and service quality, convenience usefulness, and ease of use, have been proved as enablers to promote the adoption of MCC in various contexts $[8,11,14,16,17]$. By investing in MCC, governments can reduce IT-related installation and maintenance expenditures [69] and improve information resource utilization. We believe that these perceived benefits, as motivations, may help increase the possibility of $\mathrm{m}$-Gov cloud adoption in the government and public sector $[65,70]$. Thus, the more perceived benefits, the more likely government agencies to adopt m-Gov cloud.

H1a: perceived benefit positively affects $m-G o v$ cloud adoption.

Perceived risk means the potential problems and risks brought from the introduction of innovation [7], and it is the inhibitor for technology adoption $[38,44,71]$. Dialectically, everything has two sides. As a new Internet-based technological innovation, MCC also includes several technological disadvantages that inhibit the organization from adopting, e.g., security and privacy concerns $[2,11,14,17]$. Because e-government information includes secret and private information, its security is the foundation of national and social stability. When MCC, which consists of mobile services, wireless networks, and cloud computing services, provides various and extensive services, it also has more potential security threats via threat inheritance [17, 64]. Privacy and confidentiality concerns (accidentally or deliberately disclose data for unauthorized purposes) [5], as well as abuse of user information for commercial purposes, may exacerbate perceived risks of $\mathrm{m}-\mathrm{Gov}$ cloud $[6,65,67,72,73]$. Therefore, the more the perceived risks, the fewer agencies are willing to adopt $\mathrm{m}$-Gov cloud.

$\mathrm{H} 2 \mathrm{a}$ : perceived risk negatively affects $\mathrm{m}-\mathrm{Gov}$ cloud adoption.

3.1.2. Characteristics of Providers. In addition to focusing on the technology characteristics of $\mathrm{m}$-Gov cloud, organizations should also be concerned about whether mobile cloud service providers (CSP) can provide them with reliable services [14]. The essential difference between MCC and traditional IT models is that CSP can use virtualization technology and dynamic resource configuration [74], to provide flexible and on-demand cloud services and resources [7, 25]. Therefore, agencies need to consider the impact of CSP-related characteristics when deciding on $\mathrm{m}$-Gov cloud adoption. Chang et al. indicate that the quality of technical support and training provided by CSP in the adoption process is a powerful guarantee for successful IT adoption [41]. Repschlaeger et al. proposed a set of cloud provider characteristics concerning customer preferences (e.g., flexibility, mobility, and reputation) that can allow organizations to select suitable providers $[6,75]$. Besides, computing support, reputation, and computing capacity are essential factors that influence cloud adoption [45, 63]. 
Bou Abdo et al. indicated that a trusted CSP could achieve the best privacy when located within a trusted network [14].

There is a higher standard for the security and stability of systems and information on $\mathrm{m}$-Gov cloud platform in the context of government. According to agencies' own business processes and the requirements of the system application, they should evaluate the quality of service (QoS) and servicelevel agreement (SLA) provided by CSP $[8,17,25]$. Therefore, whether CSP can provide reliable cloud service technology and management capabilities (e.g., the scientificalness of security measures, the feasibility of disaster recovery, the standardization of service, and the legality of market access and exit mechanism) according to agencies' expectations is an essential factor in the adoption of decision-making [16]. In general, those CSPs with high qualifications, large scale, superior technical capabilities, and good reputation can provide reliable $\mathrm{m}$-Gov cloud services for government agencies [39]. Therefore, the higher the perceived provider competence, the more likely the government agencies adopt $\mathrm{m}$-Gov cloud.

$\mathrm{H} 3 \mathrm{a}$ : provider competence positively affects $\mathrm{m}-\mathrm{Gov}$ cloud adoption.

3.2. Organizational Context. The organizational context, the internal context conditions that promote or restrict innovation adoption [33], describes the characteristics of an organization [32], e.g., organizational readiness, and the number of slack resources available internally $[32,39]$. As an emerging construction mode, $\mathrm{m}$-Gov cloud will bring changes and uncertainties to governments' informatization. Whether to adopt m-Gov cloud cannot be achieved by merely imitating other agencies or previous IT projects' previous experience. To a certain extent, it depends on the attitude and support of top management [10]. Meanwhile, as a complex technology-organizational revolution project, whether agencies have the necessary resources to support the adoption process and deal with the potential risk of failure will affect agencies' attitudes toward m-Gov cloud adoption. Top management support and organizational resources are two key organizational situational factors that affect $\mathrm{m}$-Gov cloud adoption and are also two components of organizational readiness [34, 40]. Therefore, we use organizational readiness to reflect the management support and resource readiness for $\mathrm{m}-\mathrm{Gov}$ cloud adoption [40].

Top management support refers to the recognition and support of leaders with decision-making authority within the organization to innovation [76]. Organizational strategy choices are generally made by top management through trade-offs between pros and cons and reflect the top management's values and cognitive bases [34, 77]. Top management can guide resource allocation, department optimization and organization integration, business process reengineering, and internal coordination $[10,36,64]$. Especially in the administrative context, $\mathrm{m}$-Gov cloud solution is generally initiated and promoted by top management. The high-level awareness and positive attitudes toward m-Gov cloud can provide adequate resources and necessary sectoral coordination for implementing $\mathrm{m}$-Gov cloud $[6,65]$.
Organizational resources are various resource elements owned and controlled by an organization [6]. It is used to determine whether an organization already has adequate resources to undertake technological innovation adoption, and adequate resources positively impact innovation adoption [41]. Resources are equally crucial to government agencies, primarily financial and human resources [54, 78]. The adoption of $\mathrm{m}$-Gov cloud (system and data migration) is a complex and long-term systematic project that will inevitably consume many human, material, and financial resources. Generally, the more the resources are available, the better the capability to withstand the risk of failure $[10,36]$. However, financial restrictions are the most common obstacle in front of innovation in the public sector [69]. If an agency has sufficient budgetary funds, adequate technical support, and affluent time, it will increase the possibility of $\mathrm{m}$-Gov cloud adoption [41].

To sum up, the higher the organizational readiness for $\mathrm{m}$-Gov cloud adoption, the easier it is for agencies to adopt m-Gov cloud.

$\mathrm{H} 4$ : organizational readiness positively affects $\mathrm{m}-\mathrm{Gov}$ cloud adoption.

3.3. Environmental Context. Environmental context is the arena in which an organization conducts business among multiple stakeholders [32], which focuses on external constraints and opportunities that affect the organizational adoption of IT innovations [33]. INT posits that an organization's rational choices are shaped by its external environmental context [54]. Unlike the simple pursuit of economic benefits by private sectors, the relationship between the government and external stakeholders is more closely linked, and its strategic objectives and value system are more complicated [31]. Due to the bureaucratic model resulting from standardization, the agency's behavior needs to be more legitimate than that of the private sector. Therefore, government agencies' decision-making behaviors are primarily related to the institutional environment in which they operate [54]. As INT emphasizes the role of external pressures on focal organizations' legitimate behaviors, in the context of governments, INT can explain external pressures primarily stemmed from superior organizations, other upstream and downstream organizations involved in using $\mathrm{m}$-Gov cloud, and citizens [55].

Superior (central) coercive pressure: as we all know, the rigid management style of heavy bureaucracy governance requires subordinates to strictly conform to structures and practices compatible with superior organizations' policies [54]. M-government development policies, central government budget, and political support of top leaders are essential factors in the behavior of local subordinate governments [65, 79]. In China, the superior (central) governments with authority attach importance to the combination of mobile cloud computing and government requirements, positioning mobile cloud computing as an innovative revolution that promotes intensive development and encourages local governments to migrate $\mathrm{m}$-Gov cloud. 
Hence, superior organizations that have adopted $\mathrm{m}$-Gov cloud are likely to exert pressure on subordinates to do likewise. Such CP stemming from superior governments are called superior coercive pressures [54]. This pressure makes subordinate governments tend to adopt $\mathrm{m}$-Gov cloud, and its construction process will present a top-down process.

Vertical and parallel agencies coercive pressure: when dominant trading partners and suppliers have adopted innovative technologies in the context of the private sector, the private sector is likely to adopt them to show its fitness as business partners [64]. Government agencies are also generally in an interconnected network to achieve cross-sectoral business processing and information sharing. Dependence on other vertical and parallel agencies arises when an agency relies heavily on other agencies for much of its input or output information [54]. Generally, input information for business processing in one agency is often the output of other agencies. Therefore, the adoption and usage of $\mathrm{m}-\mathrm{Gov}$ cloud by other vertical and parallel agencies will force agencies to follow the trend of "cloudization," and then adopt $\mathrm{m}$-Gov cloud to ensure business collaboration and data interconnection with other agencies.

Citizen expectation pressure: organizations need to adopt innovation to meet their customer needs and expectations [64]. Government agencies are often pressured by the citizens' expectations to adopt certain technologies or policies for providing excellent public services. Citizen expectation is an essential factor for the governments' adoption of technology [79]. As more and more citizens use mobile public services to handle related businesses, the citizens' expectations for further simplifying mobile business procedures, advancing the "one-stop" service process, and improving service efficiency are constantly increasing. Such pressure forces government agencies to adopt $\mathrm{m}$-Gov cloud to provide better and more versatile services to citizens and businesses [69].

In summary, $\mathrm{m}$-Gov cloud adoption is being driven from the top-level agencies as well as bubbling up from the bottom level agencies $[7,12]$. The greater the external pressure from superior, upstream, and downstream organizations, and citizens, the more the government agencies tend to adopt $\mathrm{m}-\mathrm{Gov}$ cloud.

H5: external pressure positively affects m-Gov cloud adoption.

3.4. M-Gov Cloud Trust. Trust means the trustor's subjective knowledge and confidence of the trustee [59]. In IT adoption research, trust is the adopter's expectation toward the adoptee to satisfy a specific service or fulfill a certain promise $[6,39]$. Organizations tend to adopt the innovation only if they believe that the specific characteristics of the innovative technology will ensure business process [60]. If trust is absent, even organizations that tend to adopt m-Gov cloud may sit on fence whether to adopt cloud until m-Gov cloud market matures [11, 38]. The context-sensitive nature of online-based $\mathrm{m}$-Gov cloud services raises the perceptions of security and privacy risks [73]; therefore, cloud trust can help agencies to increase the expectation of successful application of relevant $\mathrm{m}$-Gov cloud services, reduce the negative impact of uncertainty and risk in the adoption process, and then promote the willingness of cloud adoption $[12,39,50,60]$. This is when the need for trust arises in a risky situation $[2,12]$. Hence, the more the trust organizations have about m-Gov cloud, the more likely they will adopt $\mathrm{m}-\mathrm{Gov}$ cloud.

H6: M-Gov cloud trust positively affects m-Gov cloud adoption.

3.5. Mediating Effect of M-Gov Cloud Trust. Although numerous studies have discussed the direct relationship between technology characteristics and IT adoption [34, 66], there is a lack of attention to the influence mechanisms of IT adoption. Most previous studies on $\mathrm{m}$-Gov cloud adoption are no exception. Users often trust upon a new technology before adoption decision [67]. Therefore, we further explore the mechanisms (mediating effect) of cloud trust between technological context and adoption.

Trust in $\mathrm{m}$-Gov cloud technology. Trust in a specific technology reflects beliefs about the favorable attributes of a specific technology [60]. Technological characteristics can affect the shaping of trust, e.g., quality [61], reliability, information security [39], helpfulness, and functionality of a specific technology [60].

On the one hand, the perceived benefits of m-Gov cloud are especially salient for agencies to relieve concerns of potential risks (e.g., suddenly malfunction), increase confidence in successful implementation, and thus trust m-Gov cloud technology more. Therefore, the more the m-Gov cloud benefit agencies can perceive, the more the trust they will have about $\mathrm{m}$-Gov cloud. On the other hand, as a cloudbased IT service, server maintenance is mainly on the CSP side. Meanwhile, data storage, processing, and transaction are operated through a network-based cloud. Such issues may make governments face the concerns of information leakage, loss, and misuse by a hacker attack and administrator theft $[7,9]$, and these concerns will reduce confidence in $\mathrm{m}$-Gov cloud [39]. Therefore, the more the risks and uncertainties of m-Gov cloud are perceived by agencies, the fewer the trust agencies will have about m-Gov cloud.

H1b: perceived benefit positively affects m-Gov cloud trust.

H1c: cloud trust mediates the relationship between perceived benefit and cloud adoption.

$\mathrm{H} 2 \mathrm{~b}$ : perceived risk negatively affect $\mathrm{m}-\mathrm{Gov}$ cloud trust.

$\mathrm{H} 2 \mathrm{c}$ : cloud trust mediates the relationship between perceived risk and cloud adoption.

Trust in m-Gov cloud provider. McKnight et al. suggested that structural assurance and situational normality are the two dimensions of institution-based trust [59]. Due to the government and citizens' data are processed in cloud platforms, the institutional factors and structural guarantee competence of CSP are the keys to enhance trust in m-Gov 
cloud. On the one hand, CSP with such institutional factors (e.g., good reputation, success cases, and competitiveness in the cloud market) has mature technology and service competences and enables customers to believe CSP is capable of delivering reliable, secure cloud services, and meeting their customizable needs $[45,63]$. On the other hand, CSP is also the provider of the structural guarantee. The competence of CSP to manage cloud service performance in accordance with SLA commitments and use multiple technologies and solutions to meet requirements is a prerequisite for organizations to trust in CSP $[63,75]$. Such competence of CSP to provide structural guarantees (e.g., promises, contracts, regulations, and guarantees of cloud service) helps reduce concerns and enhance confidence in $\mathrm{m}$-Gov cloud, which makes the organization more confident that its own rights and interests are fully guaranteed in the use of cloud services, and makes the success of cloud service adoption more possible $[36,59]$. Therefore, the more excellent the capability of CSPs, the more the agencies' trust in m-Gov cloud.

$\mathrm{H} 3 \mathrm{~b}$ : provider competence positively affects $\mathrm{m}-\mathrm{Gov}$ cloud trust.

H3c: cloud trust mediates the relationship between provider competence and cloud adoption.

\section{Methodology}

4.1. Research Design. To test our proposed models, the research procedure, which outlines the sequence of the phase of the process involved in this research, is designed following the recommendations for applying PLS in structural equation modeling $[42,80]$. The research design comprises several steps: instrument development, data collection, and model validation. First, development and validation of the measurement instrument were conducted in three phases [63]: (1) item creation-adapted to $\mathrm{m}$-Gov cloud context from previous studies, (2) item refinement-by a panel of experts to assure clarity and validity of items, and (3) instrument pretest-by a group of 20 agencies to assure the reliability and the quality of the questionnaire. Second, the survey was distributed to actual respondents in government agencies. The unit of analysis of this study is the organization. Therefore, the survey was sent to the agencies' key informants involved in the agencies' decision-making process. A total of 93 valid responses were collected from the survey. Finally, these data were analyzed to validate the model by using PLS-SEM.

4.2. Instrument Development. A questionnaire was developed to survey government agencies in China. Based on the translation and back translation procedure [81], the constructs and corresponding items were adapted from previous studies and were revised for $\mathrm{m}$-Gov cloud context in terms of content validity based on expert reviews. The construct of perceived benefit was adapted from Hsu et al. [38] and Mohammed et al. [78], perceived risk was adapted from Hsu et al. [38] and $\mathrm{Wu}$ et al. [82], provider competence was adapted from Heart [63] and Yang et al. [83], trust of m-Gov cloud was adapted from Oliveira et al. [36] and Li et al. [39], organizational readiness was adapted from Wang and Lo [34] and Yang et al. [40], external pressure was adapted from Wang and Lo [34], and adoption of was adapted from Mohammed et al. [78] and Martins et al. [37]. All the constructs were measured through multiple reflective indicators, using a five-point Likert scale on an interval level ranging from "strongly disagree" to "strongly agree." All measurement items used to measure each of the constructs in this research are shown in Table 2. A pretest was conducted among 20 agencies that were not included in the primary survey, for testing the reliability, validity, and translational equivalence of the scales. The items were carefully assessed and revised for content validity and unambiguous wording before the questionnaires were sent.

4.3. Data Collection. The questionnaires were sent to qualified individuals at government agencies in China for data collection from October to December 2018. Based on the "key informant" approach [10, 31, 37], the roles in agencies who are in charge of $\mathrm{m}$-Gov cloud are selected as the respondents, e.g., IT directors and senior IS managers. Of the 156 questionnaires distributed, 104 were collected. Excluded invalid questionnaires with incomplete information or the same options, there were 93 valid questionnaires, with a valid response rate of $59.6 \%$. The descriptive statistics of the sample and respondents are shown in Table 3.

4.4. Data Analysis Method. PLS-SEM can predict a complicated model without any need for distribution assumptions and can handle nonnormal distributions of data and small samples [84-86]. Therefore, PLS-SEM has been applied in different contexts for adoption, e.g., mobile healthcare [47], mobile tourism shopping [48], mobile learning [49], mobile applications powered by linked data [86], mobile augmented reality [49], mobile student service [50], and cloud computing [10].

The reasons why we chose PLS-SEM are as follows: (1) our research goal is identifying key "driver" constructs for m-Gov cloud adoption, (2) the structural model is relatively complex (many constructs and many indicators), (3) the sample size is relatively small (exceed the requirements of PLS-SEM minimum sample size [84]), and (4) the data are to some extent nonnormal distribution. Therefore, PLS-SEM was used to empirically test the model, with the specific software SmartPLS 3.2.9.

\section{Data Analysis and Results}

PLS-SEM assessment typically follows a two-step process that involves separate assessments of the measurement models and the structural model [84].

5.1. Measurement Model. For the reflective measurement models, indicator reliability, internal consistency reliability, convergent validity, and discriminant validity should be assessed [85, 87]. We first need the estimates for the 
TABLE 2: Measurement items of the instrument.

\begin{tabular}{|c|c|c|c|}
\hline Construct & Item & Measurement items & References \\
\hline $\mathrm{PB}$ & $\begin{array}{l}\text { PB1 } \\
\text { PB2 } \\
\text { PB3 }\end{array}$ & $\begin{array}{l}\text { Providing m-government services over m-Gov cloud will lower the costs. } \\
\text { Using m-Gov cloud would make it easier for agencies to implement m- } \\
\text { government services. } \\
\text { Overall, using } \mathrm{m} \text {-Gov cloud would be beneficial for m-government } \\
\text { implementation. }\end{array}$ & $\begin{array}{l}\text { Hsu et al. [38] and Mohammed } \\
\text { et al. [78] }\end{array}$ \\
\hline $\mathrm{PR}$ & $\begin{array}{l}\text { PR1 } \\
\text { PR2 } \\
\text { PR3 } \\
\text { PR4 }\end{array}$ & $\begin{array}{l}\text { There is a high level of concern with data security and privacy when using m-Gov } \\
\text { cloud. } \\
\text { Adopting m-Gov cloud is associated with a high level of risk. } \\
\text { There is a high level of risk that the expected benefits of adopting m-Gov cloud will } \\
\text { not materialize. } \\
\text { Overall, I consider the adoption of m-Gov cloud to be risky. }\end{array}$ & Hsu et al. [38] and Wu et al. [82] \\
\hline PC & $\begin{array}{l}\text { PC1 } \\
\text { PC2 } \\
\text { PC3 } \\
\text { PC4 }\end{array}$ & $\begin{array}{l}\text { M-Gov cloud provider is known for its brand, competitiveness, and reputation. } \\
\text { M-Gov cloud provider provides reliable services. } \\
\text { M-Gov cloud provider keeps promises and commitments. } \\
\text { M-Gov cloud provider keeps customers' best interests in mind. }\end{array}$ & Heart [63] and Yang et al. [83] \\
\hline OR & $\begin{array}{l}\text { OR1 } \\
\text { OR2 } \\
\text { OR3 }\end{array}$ & $\begin{array}{l}\text { My agency has prepared adequate resources for m-Gov cloud adoption. } \\
\text { Higher-level agencies can assist my agency with m-Gov cloud adoption. } \\
\text { Top management in my agency encourages m-Gov cloud adoption behaviors. }\end{array}$ & Yang et al. [40] and Wang \& Lo [34] \\
\hline EP & $\begin{array}{l}\text { EP2 } \\
\text { EP3 }\end{array}$ & $\begin{array}{l}\text { The agencies at higher levels have placed much emphasis on the implementation of } \\
\text { m-Gov cloud. } \\
\text { Many agencies have placed much emphasis on the implementation of m-Gov } \\
\text { cloud. } \\
\text { The public expects m-Gov cloud to be implemented. }\end{array}$ & Wang \& Lo [34] \\
\hline TR & $\begin{array}{l}\text { TR1 } \\
\text { TR2 } \\
\text { TR3 }\end{array}$ & $\begin{array}{l}\text { M-Gov cloud is in general dependable. } \\
\text { M-Gov cloud is in general reliable. } \\
\text { M-Gov cloud is in general trustworthy. }\end{array}$ & Oliveira et al. [36] and Li et al. [39] \\
\hline $\mathrm{AD}$ & $\begin{array}{l}\mathrm{AD} 1 \\
\mathrm{AD} 2 \\
\mathrm{AD} 3\end{array}$ & $\begin{array}{l}\text { It is anticipated that my agency will adopt m-Gov cloud in the near future. } \\
\text { My agency plans to evaluate and adopt m-Gov cloud. } \\
\text { My agency is currently engaged at the initial stage of m-Gov cloud adoption. }\end{array}$ & $\begin{array}{l}\text { Mohammed [78] and Martins et al. } \\
\text { [37] }\end{array}$ \\
\hline
\end{tabular}

Table 3: Descriptive statistics of the sample and respondents.

\begin{tabular}{|c|c|c|c|}
\hline Characteristics & Category & Frequency & $\begin{array}{c}\text { Proportion } \\
(\%)\end{array}$ \\
\hline \multirow{2}{*}{ Agency nature } & $\begin{array}{c}\text { Government agencies (composition, subordinate, departmental } \\
\text { management agencies) }\end{array}$ & 84 & 90.32 \\
\hline & Institution & 9 & 9.68 \\
\hline \multirow{2}{*}{ Agency level } & Provincial level & 33 & 35.48 \\
\hline & Municipal level & 60 & 64.52 \\
\hline \multirow{3}{*}{ Information leading group } & Already established & 81 & 87.09 \\
\hline & Not established & 9 & 9.68 \\
\hline & Missing & 3 & 3.23 \\
\hline \multirow{3}{*}{ Information center or support unit } & Already established & 57 & 61.29 \\
\hline & Not established & 31 & 33.33 \\
\hline & Missing & 5 & 5.38 \\
\hline \multirow{7}{*}{ Budget for IT (Yuan) } & 0-1 million & 45 & 48.39 \\
\hline & 1-2 million & 9 & 9.68 \\
\hline & $2-5$ million & 14 & 15.05 \\
\hline & 5-10 million & 8 & 8.60 \\
\hline & 10-20 million & 9 & 9.68 \\
\hline & More than 20 million & 4 & 4.30 \\
\hline & Missing & 4 & 4.30 \\
\hline \multirow{4}{*}{$\begin{array}{l}\text { Respondent's administrative level in } \\
\text { the agency }\end{array}$} & IT director and deputy director & 23 & 24.73 \\
\hline & IT section chief (manager) & 50 & 53.76 \\
\hline & IT staff (technician) & 16 & 17.20 \\
\hline & Missing & 4 & 4.30 \\
\hline
\end{tabular}

Note: 1 CNY (Chinese Yuan) $=0.1504$ USD (United States Dollar). 
relationships between the reflective latent variables and their indicators (i.e., outer loadings). The loadings above 0.708 are recommended, as they indicate that the construct explains more than half of the indicator's variance [85]. As shown in Table 4, the outer loadings are all above 0.708 except only one indicator (i.e., PC2). Following the recommendations of previous studies $[88,89]$, removing this indicator is unnecessary as the deletion will lead to a decrease in the composite reliability (CR) and average variance extracted (AVE), as well as decrease the content validity of the measurement. Thus, the indicator reliability is acceptable.

The internal consistency reliability is evaluated by three criteria, i.e., Cronbach's $\alpha$ (CA), $\rho_{\mathrm{A}}$, and CR [85]. Table 5 shows that $\mathrm{CA}, \rho_{\mathrm{A}}$, and $\mathrm{CR}$ of all the constructs are more than the conservative threshold value of 0.707 [87], thus indicating the excellent reliability of measurement [84].

Convergent validity, the extent to which the construct converges to explain the variance of its items [12], is evaluated by the average variance extracted (AVE) [90]. An AVE higher than 0.5 has been suggested to provide empirical evidence for convergent validity, indicating that the construct explains at least 50 percent of the variance of its indicators [84]. Table 5 shows that all AVE values are above 0.5 , denoting good convergent validity [85].

Discriminant validity is the extent to which a construct is truly distinct from other constructs by empirical standards [49]. The Fornell-Larcker criterion is used to assess the discriminant validity [90], and it requires that the square root of AVE should be higher than the correlations between the constructs [84]. Table 5 shows that the discriminant validity of all constructs is supported.

5.2. Structural Model. When the measurement model assessment is satisfactory, the next step is assessing the structural model. In contrast to CB-SEM approach that is based on goodness-of-fit measures to assess the structural model, in PLS-SEM, the structural model is verified by examining the coefficient of determination $\left(R^{2}\right)$, predictive relevance (Stone-Geisser's $Q^{2}$ ) [91, 92], the statistical significance and relevance of the path coefficients, and the effect sizes $\left(f^{2}\right)[85,87]$. During this stage, the hypotheses are tested to determine whether they obey the established relationships in our proposed model [10].

Structural model coefficients for the relationships between the constructs are derived from estimating a series of regression equations. Multicollinearity must be examined to make sure it does not bias the regression results, before assessing the structural relationships [85]. Therefore, multicollinearity is investigated through the variance inflation factor (VIF) [87]. As shown in Table 5, all VIF values are in the range of 1.393 to 2.48 . These are below the most stringent cutoff of 3 [88], indicating an absence of multicollinearity.

The significance of estimates is obtained by performing a bootstrapping procedure with 5000 iterations of resampling [84]. The structural model's estimated relationships are shown in Figure 2, where the explained variance of endogenous variables $\left(R^{2}\right)$ and the standardized path coefficients $(\beta)$ are presented.
As depicted in Figure 2, provider competence $(\beta=0.217$, $p<0.01)$, organizational readiness $(\beta=0.191, p<0.05)$, external pressure $(\beta=0.214, p<0.01)$, and $\mathrm{m}$-Gov cloud trust $(\beta=0.344, \quad p<0.001)$ have significant positive effects on $\mathrm{m}-\mathrm{Gov}$ cloud adoption. Thus, hypotheses H3a, H4, H5, and H6 are supported. Interestingly, perceived benefit and perceived risk have insignificant direct relationships with $\mathrm{m}$-Gov cloud adoption by government agencies. Thus, H1a and $\mathrm{H} 2 \mathrm{a}$ are not supported. Furthermore, for the predictors of cloud trust, perceived benefit $(\beta=0.400, p<0.001)$ and provider competence $(\beta=0.311, p<0.01)$ have significant positive effects on $\mathrm{m}$-Gov cloud trust, respectively, supporting $\mathrm{H} 1 \mathrm{~b}$ and $\mathrm{H} 3 \mathrm{~b}$, while perceived risk $(\beta=-0.149$, $p>0.05$ ) has no significant effect, rejecting $\mathrm{H} 2 \mathrm{~b}$. Table 6 provides a summary of the results for nine direct hypotheses that were developed between constructs.

The most commonly used criterion to evaluate the structural model is the $R^{2}$ value [93], commonly used to assess the goodness of fit in regression analysis [87]. $R^{2}$ is a measure of the model's explanatory power and referred to as in-sample predictive power [85]. As a guideline, $R^{2}$ values of $0.75,0.50$, and 0.25 can be considered substantial, moderate, and weak [42]. As depicted in Figure 2, our proposed model explained $52.3 \%$ of the variance $\left(R^{2}\right)$ in $\mathrm{m}$-Gov cloud trust and $68.3 \%$ of the variance $\left(R^{2}\right)$ in $\mathrm{m}-\mathrm{Gov}$ cloud adoption, respectively, indicating moderate explanatory power.

In addition to examining the $R^{2}$ of all endogenous constructs, the model is evaluated by the effect size $f$. The effect size $f^{2}$ allows us to assess how removing a certain predictor construct affects the change in $R^{2}$ value of an endogenous construct, that is, an exogenous construct contribution to an endogenous construct's $R^{2}$ [94]. As a rule of thumb, values higher than $0.02,0.15$, and 0.35 indicate small, medium, and large $f^{2}$ effect sizes, respectively [85]. The $f^{2}$ effect size for the exogenous constructs is presented in Table 7. Perceived benefit (0.196) has a medium size effect, while perceived risk (0.33) and provider competence (0.131) have a small size effect toward trust. Trust (0.166) has a medium size effect, perceived benefit (0.02), provider competence $(0.081)$, organizational readiness $(0.083)$, and external pressure (0.087) have small size effects, while perceived risk (0.003) has no effect size toward adoption.

In addition to $R^{2}$ values as a criterion of predictive accuracy power, the predictive relevance criterion should be tested for assessing the structural model [91, 92]. The $Q^{2}$ value, an evaluation criterion of the model's predictive relevance (out-of-sample predictive power), is calculated via the blindfolding procedure that is a sample re-use technique [88]. As a guideline, $Q^{2}$ values higher than $0,0.25$, and 0.50 depict small, medium, and large predictive relevance of the PLS-path model [85]. As shown in Table 7, the $Q^{2}$ value for adoption is 0.457 , which is greater than 0.25 , indicating that all the exogenous constructs have medium predictive relevance for the endogenous construct. Like the $f^{2}$ effect sizes, the $q^{2}$ effect sizes can be computed to assess an exogenous construct contribution to an endogenous latent variable's $Q^{2}$ value [88]. As a relative measure of predictive relevance, $q^{2}$ values of $0.02,0.15$, and 0.35 indicate that an exogenous construct has a small, medium, or large predictive relevance 
TABLE 4: Descriptive statistics for items and constructs.

\begin{tabular}{|c|c|c|c|c|c|c|c|c|c|}
\hline Construct & Item & Mean & $\mathrm{SD}$ & Kurtosis & Skewness & Loadings & VIF & Kurtosis & Skewness \\
\hline \multirow{3}{*}{ Perceived benefit } & PB1 & 3.892 & 0.695 & 0.915 & -0.631 & 0.789 & 1.388 & \multirow{3}{*}{1.896} & \multirow{3}{*}{-0.679} \\
\hline & PB2 & 3.828 & 0.650 & 0.339 & -0.290 & 0.843 & 1.560 & & \\
\hline & PB3 & 3.871 & 0.643 & 0.588 & -0.367 & 0.763 & 1.353 & & \\
\hline \multirow{4}{*}{ Perceived risk } & PR1 & 2.849 & 0.927 & -0.451 & 0.390 & 0.790 & 1.711 & \multirow{4}{*}{0.578} & \multirow{4}{*}{0.902} \\
\hline & PR2 & 2.527 & 0.862 & 0.255 & 0.784 & 0.870 & 2.297 & & \\
\hline & PR3 & 2.699 & 0.827 & 0.359 & 0.734 & 0.870 & 2.402 & & \\
\hline & PR4 & 2.720 & 0.896 & 0.071 & 0.678 & 0.823 & 1.922 & & \\
\hline \multirow{4}{*}{ Provider competence } & PC1 & 3.946 & 0.781 & 0.270 & -0.593 & 0.760 & 1.374 & \multirow{4}{*}{4.065} & \multirow{4}{*}{-1.601} \\
\hline & PC2 & 3.742 & 0.702 & 1.842 & -0.725 & 0.681 & 1.254 & & \\
\hline & PC3 & 3.742 & 0.732 & 1.532 & -0.721 & 0.728 & 1.417 & & \\
\hline & PC4 & 3.860 & 0.727 & 2.344 & -0.970 & 0.753 & 1.369 & & \\
\hline \multirow{3}{*}{ Organizational readiness } & OR1 & 3.710 & 0.742 & -0.074 & -0.272 & 0.778 & 1.289 & \multirow{3}{*}{0.102} & \multirow{3}{*}{-0.484} \\
\hline & OR2 & 3.645 & 0.757 & -0.204 & -0.205 & 0.846 & 1.483 & & \\
\hline & OR3 & 3.527 & 0.784 & -0.397 & 0.114 & 0.748 & 1.430 & & \\
\hline \multirow{3}{*}{ External pressure } & EP1 & 3.849 & 0.747 & 0.353 & -0.531 & 0.851 & 1.494 & \multirow{3}{*}{0.086} & \multirow{3}{*}{-0.361} \\
\hline & $\mathrm{EP} 2$ & 3.624 & 0.815 & -0.424 & -0.166 & 0.805 & 1.702 & & \\
\hline & EP3 & 3.828 & 0.9 & -0.610 & -0.371 & 0.838 & 1.737 & & \\
\hline \multirow{3}{*}{ Trust of m-Gov cloud } & TR1 & 3.882 & 0.701 & 0.771 & -0.591 & 0.841 & 1.551 & \multirow{3}{*}{2.002} & \multirow{3}{*}{-1.154} \\
\hline & TR2 & 3.774 & 0.658 & 0.463 & -0.409 & 0.840 & 1.666 & & \\
\hline & TR3 & 3.828 & 0.616 & 0.791 & -0.437 & 0.761 & 1.371 & & \\
\hline \multirow{3}{*}{ Adoption of m-Gov cloud } & $\mathrm{AD} 1$ & 3.989 & 0.726 & 1.307 & -0.841 & 0.853 & 1.629 & \multirow{3}{*}{1.263} & \multirow{3}{*}{-0.638} \\
\hline & $\mathrm{AD} 2$ & 3.624 & 0.732 & -0.092 & -0.273 & 0.826 & 1.701 & & \\
\hline & AD3 & 3.839 & 0.708 & 1.224 & -0.866 & 0.836 & 1.653 & & \\
\hline
\end{tabular}

Note: standard deviation, SD; variance inflation factor, VIF.

TABLE 5: Reliability, convergent, and discriminant validity.

\begin{tabular}{|c|c|c|c|c|c|c|c|c|c|c|c|c|c|}
\hline & $\mathrm{CA}$ & $\rho_{\mathrm{A}}$ & $\mathrm{CR}$ & AVE & VIF (TR) & VIF (AD) & $\mathrm{PB}$ & PR & $\mathrm{PC}$ & OR & $\mathrm{EP}$ & TR & $\mathrm{AD}$ \\
\hline $\mathrm{PB}$ & 0.717 & 0.721 & 0.855 & 0.639 & 1.715 & 2.480 & 0.799 & & & & & & \\
\hline PR & 0.859 & 0.864 & 0.905 & 0.704 & 1.399 & 1.548 & -0.508 & 0.839 & & & & & \\
\hline PC & 0.710 & 0.715 & 0.821 & 0.534 & 1.558 & 1.827 & 0.578 & -0.428 & 0.731 & & & & \\
\hline OR & 0.707 & 0.727 & 0.834 & 0.627 & & 1.393 & 0.434 & -0.316 & 0.421 & 0.792 & & & \\
\hline EP & 0.781 & 0.804 & 0.870 & 0.692 & & 1.670 & 0.554 & -0.147 & 0.312 & 0.393 & 0.832 & & \\
\hline TR & 0.746 & 0.755 & 0.855 & 0.664 & & 2.250 & 0.656 & -0.485 & 0.606 & 0.426 & 0.483 & 0.815 & \\
\hline $\mathrm{AD}$ & 0.790 & 0.797 & 0.877 & 0.703 & & & 0.657 & -0.374 & 0.627 & 0.555 & 0.586 & 0.722 & 0.838 \\
\hline
\end{tabular}

Note: The diagonal elements in bold are the square root of AVE; perceived benefit, PB; perceived risk, PR; provider competence, PC; organizational readiness, OR; external pressure, EP; trust of m-Gov cloud, TR; adoption of m-Gov cloud, AD.

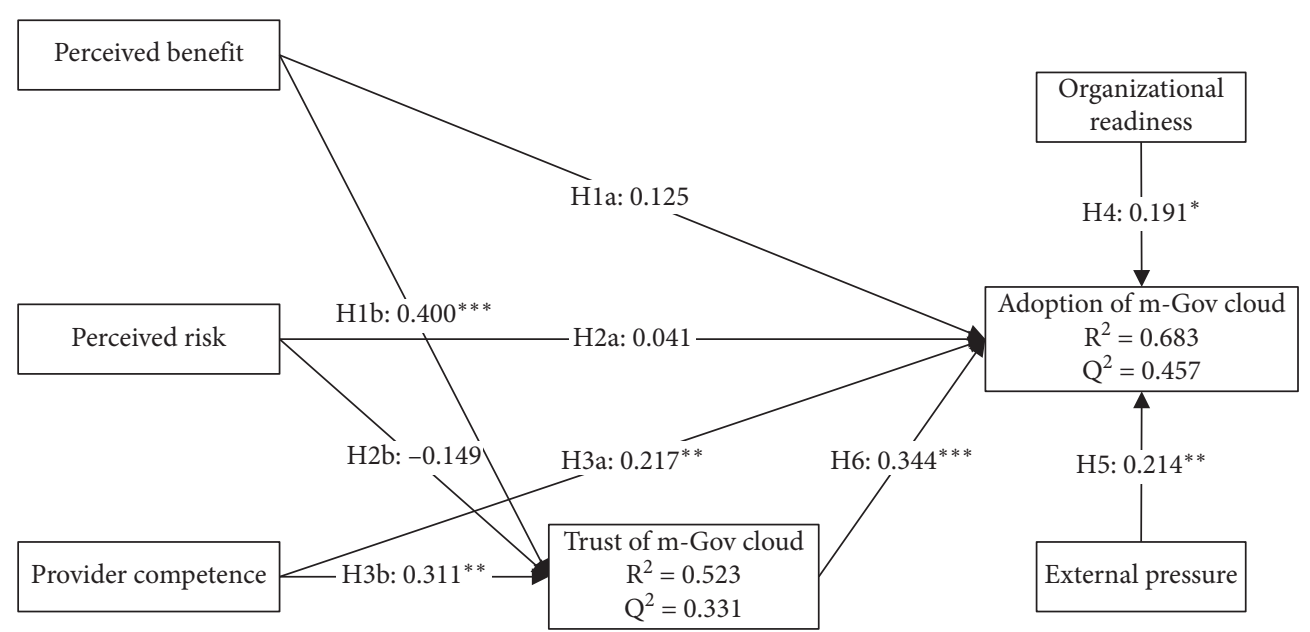

FIGURE 2: Estimated relationships of the structural model. 
TABLE 6: Summary of the results for hypothesis testing.

\begin{tabular}{lcccccccc}
\hline Hyp. & Structural path & $\beta$ & SE & $T$ value & $p$ value & BCa 95\% LB & BCa 95\% UB & Supported \\
\hline H1b & Perceived benefit $\longrightarrow$ trust & $0.400^{* * *}$ & 0.092 & 4.326 & 0.0001 & 0.214 & 0.581 \\
H2b & Perceived risk $\longrightarrow$ trust & -0.149 & 0.077 & 1.926 & 0.054 & -0.286 & 0.019 & Yes \\
H3b & Provider competence $\longrightarrow$ trust & $0.311^{* *}$ & 0.099 & 3.142 & 0.002 & 0.114 & 0.505 & No \\
H1a & Perceived benefit $\longrightarrow$ adoption & 0.125 & 0.116 & 1.083 & 0.279 & -0.094 & 0.355 & No \\
H2a & Perceived risk $\longrightarrow$ adoption & 0.041 & 0.084 & 0.493 & 0.622 & -0.127 & 0.199 & No \\
H3a & Provider competence $\longrightarrow$ adoption & $0.217^{* *}$ & 0.082 & 2.638 & 0.008 & 0.069 & 0.389 & Yes \\
H4 & Organizational readiness $\longrightarrow$ adoption & $0.191^{*}$ & 0.084 & 2.280 & 0.023 & 0.027 & 0.355 \\
H5 & External pressure $\longrightarrow$ adoption & $0.214^{* *}$ & 0.081 & 2.629 & 0.009 & 0.040 & 0.362 & Yes \\
H6 & Trust $\longrightarrow$ adoption & $0.344^{* * *}$ & 0.087 & 3.935 & 0.0001 & 0.174 & 0.514 & Yes \\
\hline
\end{tabular}

Note: $\beta$, standard $\beta$; SE, standard error; $\mathrm{BCa}$, bias-corrected and accelerated bootstrap confidence interval; LB, lower bound; UB, upper bound; ${ }^{*} p<0.05$; ${ }^{* *} p<0.01 ;{ }^{* * *} p<0.001$.

TABLE 7: The result of the predictive relevance of endogenous constructs.

\begin{tabular}{|c|c|c|c|c|c|c|}
\hline Constructs & $R^{2}$ & $f^{2}$ & Explanatory power & $Q^{2}$ & $q^{2}$ & Predictive relevance \\
\hline Perceived benefit & & 0.020 & Small & & 0.004 & No effect \\
\hline Perceived risk & & 0.003 & No effect & & -0.004 & No effect \\
\hline Provider competence & & 0.081 & Small & & 0.028 & Small \\
\hline Organizational readiness & & 0.083 & Small & & 0.026 & Small \\
\hline External pressure & & 0.087 & Small & & 0.031 & Small \\
\hline Trust & & 0.166 & Medium & & 0.066 & Small \\
\hline Adoption & 0.683 & & & 0.457 & & \\
\hline
\end{tabular}

for a specific endogenous construct, respectively [88]. As Table 7 shows, a small $q^{2}$ effect size is observed for provider competence, organizational readiness, external pressure, and trust, while perceived benefit and perceived risk have no effect size of predictive relevance toward the endogenous construct (i.e., adoption).

5.3. Mediation Test. Analyzing the strength of the mediator variable's relationships with the other constructs allows substantiating the mechanisms that underlie the cause-effect relationship between an exogenous construct and an endogenous construct $[2,11,85]$. Baron and Kenny's procedure [95] and Sobel's four-step approach [96] for determining mediating effects are so well known and widely used in various studies $[2,11,97]$. However, the Sobel test is not appropriate for analyzing indirect effects [98, 99], and this stepwise approach is not necessary as PLS can test mediating effects in a single model at once [99]. As suggested by Hair et al. [88] and Hayes [100], 5000 iterations of the bootstrapping procedure, a nonparametric resampling procedure that imposes no assumptions on the normality of sampling distribution [98], are used to estimate the $95 \%$ bias-corrected confidence interval for the direct, indirect, and total effects [97]. Compared to the Sobel test, a bootstrapping procedure for mediation testing via PLS-SEM could be achieved with smaller sample sizes while still achieving higher statistical power levels $[88,89]$. Table 8 presents the mediation analysis outcomes, associated with hypotheses $\mathrm{H} 1 \mathrm{c}, \mathrm{H} 2 \mathrm{c}$, and $\mathrm{H} 3 \mathrm{c}$.

Following the guidelines of mediation analysis procedure [88], we conclude that cloud trust fully mediates the relationship between perceived benefit to cloud adoption, as the indirect effect (the mediated path) for the relationship (perceived benefit $\longrightarrow$ m-Gov cloud adoption) is statistically significant, and the direct effect is statistically nonsignificant, supporting H1c. As neither the indirect effect nor the direct effect of perceived technology risk on $\mathrm{m}$-Gov cloud adoption is found to be significant, we demonstrate that cloud trust has no mediation effect of perceived technology risk on $\mathrm{m}-\mathrm{Gov}$ cloud adoption, rejecting H2c. Since both the indirect effect and the direct effect of provider competence on $\mathrm{m}$-Gov cloud adoption are significant, we conclude that cloud trust partially mediates the relationship, supporting $\mathrm{H} 3 \mathrm{c}$. Furthermore, as the indirect and the direct effects are both positive, the sign of their product is also positive. Hence, we substantiate that cloud trust shows the complementary mediation of this relationship.

\section{Discussion}

6.1. Principal Findings. This study not only identifies the determinants of $\mathrm{m}$-Gov cloud adoption by using an integrated model that combines TOE, TFT, INT, and trust theory, but also reveals their influence mechanisms (i.e., mediation effect). The results show that the adoption decision of $\mathrm{m}$-Gov cloud is affected by multiple perspectives, e.g., technological characteristics, organizational readiness, external pressure, and particularly trust. The results also indicate that the technological characteristics of $\mathrm{m}-\mathrm{Gov}$ cloud are antecedents of cloud trust. The discussion of the results is presented below.

First, the significant positive effect of cloud trust on the adoption of $\mathrm{m}$-Gov cloud was observed, with the highest degree of influence $(\beta=0.344)$ among all factors. This finding corresponds to previous studies on trust in technology $[6,12,39,63,67]$. The decision must be accompanied by trust to confirm innovative technology adoption [11]. It means that 
TABLE 8: Mediation test.

\begin{tabular}{|c|c|c|c|c|c|c|c|c|}
\hline Mediation path & Effect & $\beta$ & SE & $T$ value & $p$ value & BCa $95 \%$ LB & BCa 95\% UB & Conclusion \\
\hline \multirow{3}{*}{ Perceived benefit $\longrightarrow$ adoption via trust } & Direct & 0.125 & 0.116 & 1.083 & 0.279 & -0.094 & 0.355 & Indirect-only \\
\hline & Indirect & $0.138^{* *}$ & 0.045 & 3.089 & 0.002 & 0.070 & 0.259 & Full mediation \\
\hline & Total & $0.263^{*}$ & 0.111 & 2.374 & 0.018 & 0.054 & 0.485 & H1c Supported \\
\hline \multirow{3}{*}{ Perceived risk $\longrightarrow$ adoption via trust } & Direct & 0.041 & 0.084 & 0.493 & 0.622 & -0.127 & 0.199 & No effect \\
\hline & Indirect & -0.051 & 0.031 & 1.647 & 0.100 & -0.126 & -0.002 & No mediation \\
\hline & Total & -0.010 & 0.088 & 0.113 & 0.910 & -0.179 & 0.161 & H2c Rejected \\
\hline \multirow{3}{*}{ Provider competence $\longrightarrow$ adoption via trust } & Direct & $0.217^{* *}$ & 0.082 & 2.638 & 0.008 & 0.069 & 0.389 & Complementary \\
\hline & Indirect & $0.107^{*}$ & 0.045 & 2.391 & 0.017 & 0.035 & 0.221 & Partial mediation \\
\hline & Total & $0.324^{* * *}$ & 0.093 & 3.472 & 0.001 & 0.152 & 0.519 & H3c Supported \\
\hline
\end{tabular}

Note: ${ }^{*} p<0.05 ;{ }^{* *} p<0.01 ;{ }^{* * *} p<0.001$.

when agencies believe that $\mathrm{m}$-Gov cloud is reliable and has enough confidence in cloud service, they are more inclined to adopt $\mathrm{m}$-Gov cloud. With regard to the sources of cloud trust, the perceived benefit and provider competence, as antecedents, have significant direct effects on $\mathrm{m}$-Gov cloud trust, which suggests that trust in the information technology itself (i.e., perceived benefit) [60] and trust in specific Internet vendors (i.e., provider competence) [59] play roles in shaping IT-related beliefs. Therefore, this study provides further support for the importance of trust in understanding $\mathrm{m}-\mathrm{Gov}$ cloud adoption among government agencies.

Furthermore, we found perceived benefit from technological context has an indirect effect on cloud service adoption with a full mediation of cloud service trust. We also found that provider competence from the technological context has an indirect effect on cloud service adoption with a partial mediation of cloud service trust. The mediating role of trust suggests that trust-building is one underlying interpretive mechanism of how technological factors can result in IT innovation adoption.

Second, for technological characteristics, interestingly, the direct effect of perceived benefit on the adoption of $\mathrm{m}$-Gov cloud is insignificant, which is contrary to previous studies that emphasize the significance of technological benefits $[34,38,44,70,101]$. However, perceived benefits have a significant total effect (i.e., direct effect and indirect effect combined) on cloud adoption with the full mediation of cloud trust. This finding may reflect a crucial problem for both academia and industry, i.e., the adoption and diffusion of IT innovation in governments and public sectors lag far behind that of the private sectors [31, 102], despite the potential benefits for governments. Generally, the adoption decision may be more complicated than private sectors because of the different characteristics of public sectors from for-profit enterprises (e.g., nonprofit orientation, the political or bureaucratic nature, and their stakeholders' diversity) [103]. These characteristics make government lack innovativeness and run into the conservative mindset that shunts governments into risk-averse positions and tends to use more mature technology. Therefore, as a rational decision-maker, the agency will make the adoption decision based on the sufficient benefit-risk analysis, rather than technology advantages itself in isolation.

Organizations may view risk as a drawback to cloud adoption $[2,11,12,104]$. Surprisingly, as different from previous studies (significant effect of security and privacy risks on IT adoption for organizations) [5-7, 35], neither direct nor indirect effect of perceived risk is statistically significant on $\mathrm{m}-\mathrm{Gov}$ cloud adoption. Similar findings are reported in earlier studies [34, 36, 37, 64, 67]. It may be that the recent advancements in MCC ensure confidentiality, integrity, and security of cloud services in the mobile cloud environment, e.g., cloud-based trust management scheme [26], and encrypted mobile cloud data in public key system [9]. In addition, CSP also provides users with various security-related services and software, including personal authentication, virus scanning and detection, and private information protection [16]. Therefore, agencies are more confident in the increasing efforts of $\mathrm{m}$-Gov cloud providers to ensure data security and privacy [36]. Another possible explanation is that newly established national standards and regulations provide agencies technological guidance for introducing MCC, helping them shape organizational trust and control over technical, organizational, and institutional risks. Besides, as the maturity and extensive application of MCC, organizations have reached a point at which MCC's security concerns may not outweigh its benefits, rather than more focus on its risk at its initial market stage. Accordingly, perceived risks are not the main factors that influence government agency's adoption decision on m-Gov cloud.

Both the direct and indirect effects of provider competence on the adoption of $\mathrm{m}$-Gov cloud are significant, consistent with previous research [41, 63]. M-Gov cloud is not just an IT product, but a service innovation. A reputable and capable CSP can not only provide reliable cloud services according to agencies' expectations, but also reduce the technical risks in the implementation of $\mathrm{m}$-Gov cloud, which may help agencies have more confidence in the increasing efforts of CSP and improve the possibility of adoption.

Third, external pressure has a significant positive impact on $\mathrm{m}$-Gov cloud adoption, consistent with previous IT innovation adoption studies $[34,54,79,101]$. This result is unsurprising because that government has stringent rules and hierarchies, and subordinate agencies must abide by superiors' orders, which is the basis for bureaucracy's normal operation. Therefore, external pressures from superior agencies, other upstream and downstream agencies, and citizens significantly influence the adoption of $\mathrm{m}-\mathrm{Gov}$ cloud among government agencies. 
Fourth, organizational readiness has a significant positive effect on $\mathrm{m}$-Gov cloud adoption, which is supported by earlier studies [34, 40, 41, 54]. However, the degree of influence $(\beta=0.191)$ is lower than other determinants. The possible explanations include the following: first, in the government context, top managements are usually not proficient in mobile cloud computing. Although they have to show a supportive attitude due to superiors' pressure, they did not really push forward $\mathrm{m}$-Gov cloud adoption process that is also regarded as apathy behavior of resistance to IT implementation $[105,106]$. Second, on-demand self-service, as the essential characteristics of $\mathrm{m}-\mathrm{Gov}$ cloud, may reduce the requirements of initial investment and IT resources. Hence, the initial installation and maintenance costs are not relatively crucial for $\mathrm{m}-\mathrm{Gov}$ cloud adoption.

6.2. Theoretical Implications. First, our findings make essential contributions to $\mathrm{m}-\mathrm{Gov}$ cloud adoption literature on factors that influence $\mathrm{m}$-Gov cloud adoption in government agencies. Previous studies on $\mathrm{m}-\mathrm{Gov}$ cloud focus on the benefits and challenges analysis [20, 21], architecture and framework of design, implementation, and deployment $[23,24]$. Few studies have developed an integrated model for systematically examining determinants of $\mathrm{m}$-Gov cloud adoption in government agencies from innovation adoption perspectives. From a comprehensive perspective, our study reveals the determinants and influence mechanisms of $\mathrm{m}$-Gov cloud adoption, which makes up for the research of $\mathrm{m}$-Gov cloud adoption and understand the insight of $\mathrm{m}-\mathrm{Gov}$ cloud adoption.

Second, this study's findings complement and extend innovation adoption studies. As different theories emphasize the different insights, researchers have called for holistic approaches that integrate more than one theoretical perspective $[10,36,37,62]$, in order to make full use of the advantages of different models, and make up for the onesidedness of a single model, thereby effectively improving the validation of the integrated model. This study develops an integrated model incorporating TOE framework, TFT, INT, and trust theory, and the model effectively identifies the determinants and explains the mechanisms of $\mathrm{m}$-Gov cloud adoption, with a moderate explanatory power $\left(R^{2}=69.3 \%\right)$, which enriches the research on IT innovation adoption at the organizational level, especially in the government field.

Third, this study reveals the mediating role of trust, complementing, and extending trust theory studies for government agency context. Most importantly, this study moves beyond the dominant research paradigm that technological context's factors directly result in IT innovation adoption in organizations $[34,66]$. We use an often neglected, yet profound, tie between adoption and trust to reveal a sequential mediating process, in which technological context's factors have primary effects on cloud trust-building that sequentially influences organizations' cloud adoption, i.e., the mediation effects of cloud trust between cloud characteristics and cloud adoption. Such trust in the information technology itself (i.e., benefit and risk) [60] and trust in specific Internet vendors (i.e., provider competence)
[59] should be embedded in the cloud adoption studies. This is in accordance with the findings from Oliveira et al. linking performance expectancy and behavioral intention to adopt mobile banking [62]. The sequential mediating effects revealed in this study imply an essential trust-building process of IT innovation adoption. Therefore, as IT innovation adoption and diffusion involves a complicated process, more effort should be devoted to exploring underlying mechanisms between external technological factors and IT adoption decisions in organizations [39].

6.3. Managerial Implications. This research offers important practical implications for policy-making agencies, government agencies, and CSP involved in adopting and implementing $\mathrm{m}$-Gov cloud services.

The findings may help policy-making agencies develop more effective strategies that encourage government agency's adoption of $\mathrm{m}$-Gov cloud while devising appropriate initiation strategies. First, as trust is an important antecedent [50], policy-makers should consider how to increases agencies' trusting beliefs about the characteristics of m-Gov cloud technology and provider. We propose that relevant policy-makers should collaborate with CSPs to jointly conduct a series of seminars and training sessions involving related agencies' top management and staff [10], to increase their understanding about $\mathrm{m}$-Gov cloud, thus eliminating the concerns on technological risks and uncertainties, and increasing trust in $\mathrm{m}-\mathrm{Gov}$ cloud technology and provider. Second, policy-making agencies may perceive the importance of external pressures resulting in $\mathrm{m}-\mathrm{Gov}$ cloud adoption, such as a considerable emphasis from superior agencies, other upstream and downstream agencies, and citizen expectations. Thus, policy-makers are advised to encourage government agency adoption of $\mathrm{m}$-Gov cloud via institutional guarantee and interorganizational learning [34]. For example, policy-makers can provide a stable institutional guarantee environment (e.g., top-level design plan, financial budgets, and standards) for the long-term construction of $\mathrm{m}$-Gov cloud, for avoiding the failure of $\mathrm{m}$-Gov cloud investment due to policy changes. Besides, agencies should strengthen exchanges and interorganizational learning, and they can follow the standard operation process of best practice recommended by the superior department. Third, policy-makers need to consider organizational readiness when formulating promotion policies of $\mathrm{m}$-Gov cloud adoption. As organizational choices reflect the top managers' values and cognitive bases [34], policy-makers should focus more on training and motivating top managers to support the adoption process, to supervise whether necessary resources can support m-Gov cloud adoption, and to guide all staffs to overcome organizational inertia and create a "cloud" cultures or a supportive environment/climate [12]. For example, the depth and breadth of m-Gov cloud adoption should be regarded as a key performance indicator (KPI) of performance evaluation for agencies and top managers $[28,65]$.

The findings of this study provide marketing suggestions for CSP. When encouraging government agencies' adoption 
of m-Gov cloud, CSP should highlight how agencies can benefit from investing in $\mathrm{m}$-Gov cloud and emphasize they have the ability to be competent in providing security and reliable m-Gov cloud services. On the one hand, CSP should help agencies understand what benefits they will gain, though improving the perceived attributes of trialability and observability of m-Gov cloud [64], e.g., demonstration of the successful cases and free trial. For example, with the trialability, agencies are more likely to prefer trying $\mathrm{m}$-Gov cloud before adopting, as they would like to be confident that these technologies meet their expectations [64]. On the other hand, CSPs and industry associations should occasionally hold seminars and $\mathrm{m}$-Gov cloud service exhibitions to show the brand, qualifications, reputation, and cloud service products of CSPs, in order to build trust in CSPs. Besides, CSPs should strengthen the security of m-Gov cloud technology and service capabilities for providing reliable services.

6.4. Limitations and Future Directions. This study has several limitations. First, the sample size (93) is relatively small, and larger sample size is required to generalize further [4]. Second, this study was conducted in a single country, China, which implies that our findings' generalizability can be limited, due to differences in the cultural environment [64] and political system [34]. Therefore, future studies may consider a comparative study across different countries to address this concern. Third, innovation adoption is a dynamic process evolving $[7,12]$, and the innovation process in public organizations consists of several stages and steps [69]. However, our study does not use a longitudinal perspective on the diffusion stages [31]. Hence, further research may assess $\mathrm{m}$-Gov cloud diffusion over an extended period of time.

\section{Conclusions}

MCC is one of the most important mobile-Internet developments and represents an essential step forward for information systems [10]. In the context of governments, the governments can make full use of the benefits of MCC to improve their capabilities without the cost of installing new infrastructure or software, reduce the initial installation and maintenance costs, improve IT resource utilization efficiency, and improve public service satisfaction, according to introducing MCC into government services [31]. It is essential to understand the determinants and mechanisms that can reveal and acquire insight into challenges associated with this emerging trend. However, for governments, the adoption process is neither easy nor quick and depends on many determinants that the present study seeks to identify. Therefore, from a comprehensive perspective, an integrated model based on TOE framework, TFT, INT, and trust theory was developed to explore the determinants and reveal mechanisms that influence the adoption of $\mathrm{m}-\mathrm{Gov}$ cloud in Chinese context.

Interestingly, the data describe a more complex picture than might have been anticipated. We found that provider competence, organizational readiness, external pressure, and trust of $\mathrm{m}$-Gov cloud have significant effects on $\mathrm{m}$-Gov cloud adoption, while perceived benefit and perceived risk have no direct significant effect on $\mathrm{m}$-Gov cloud adoption. Besides, perceived benefit, perceived risk, and provider competence have significant effects on $\mathrm{m}$-Gov cloud trust. M-Gov cloud trust plays an indirect-only (full) mediation and complementary (partial) mediation effect between perceived benefit, provider competence, and $\mathrm{m}$-Gov cloud adoption, respectively. This study, therefore, suggests that trust is a mediating variable between external technology variables and adoption. Our findings offer valuable insights to organizational decision-makers, IT managers, and IS researchers who may wish to examine the adoption of $\mathrm{m}$-Gov cloud in a government agency.

\section{Data Availability}

The data used to support the findings of this study are available from the corresponding author upon request.

\section{Conflicts of Interest}

The authors declare that there are no conflicts of interest regarding the publication of this paper.

\section{Acknowledgments}

This work was supported by the National Social Science Fund of China (20FGLB070), Shandong Provincial Natural Science Foundation of China (ZR2019BG004 and ZR2020MG075), and the National Natural Science Foundation of China (72072103).

\section{References}

[1] Y.-R. Shin and E.-N. Huh, "mCSQAM: service quality assessment model in mobile cloud services environment," Mobile Information Systems, vol. 2016, Article ID 2517052, 9 pages, 2016.

[2] R. Raut, P. Priyadarshinee, and M. Jha, "Understanding the mediation effect of cloud computing adoption in Indian organization," International Journal of Service Science, Management, Engineering, and Technology, vol. 8, no. 3, pp. 40-59, 2017.

[3] I. Arpaci, "Understanding and predicting students' intention to use mobile cloud storage services," Computers in Human Behavior, vol. 58, pp. 150-157, 2016.

[4] I. Arpaci, "Antecedents and consequences of cloud computing adoption in education to achieve knowledge management," Computers in Human Behavior, vol. 70, pp. 382-390, 2017.

[5] I. Arpaci, K. Kilicer, and S. Bardakci, "Effects of security and privacy concerns on educational use of cloud services," Computers in Human Behavior, vol. 45, pp. 93-98, 2015.

[6] P. Priyadarshinee, R. D. Raut, M. K. Jha, and B. B. Gardas, "Understanding and predicting the determinants of cloud computing adoption: a two staged hybrid SEM-neural networks approach," Computers in Human Behavior, vol. 76, pp. 341-362, 2017.

[7] P. Priyadarshinee, M. K. Jha, R. D. Raut, and M. G. Kharat, "To measure the business performance through cloud 
computing adoption in Indian scenario: structural equation modelling," International Journal of Business Information Systems, vol. 28, no. 4, pp. 468-503, 2018.

[8] A. A. Alsaffar, H. P. Pham, C.-S. Hong, E.-N. Huh, and M. Aazam, "An architecture of IoT service delegation and resource allocation based on collaboration between fog and cloud computing," Mobile Information Systems, vol. 2016, Article ID 6123234, 15 pages, 2016.

[9] Y. Zhang, Y. Li, and Y. Wang, "Conjunctive and disjunctive keyword search over encrypted mobile cloud data in public key system," Mobile Information Systems, vol. 2018, Article ID 3839254, 11 pages, 2018.

[10] P. R. Palos-Sanchez, F. J. Arenas-Marquez, and M. AguayoCamacho, "Cloud computing (SaaS) adoption as a strategic technology: results of an empirical study," Mobile Information Systems, vol. 2017, Article ID 2536040, 20 pages, 2017.

[11] P. Priyadarshinee, "Examining critical success factors of cloud computing adoption," International Journal of Decision Support System Technology, vol. 12, no. 2, pp. 80-96, 2020.

[12] P. Priyadarshinee, "Cloud computing adoption," International Journal of Cloud Applications and Computing, vol. 8, no. 1, pp. 97-116, 2018.

[13] I. Arpaci, "A hybrid modeling approach for predicting the educational use of mobile cloud computing services in higher education," Computers in Human Behavior, vol. 90, pp. 181-187, 2019.

[14] J. Bou Abdo, T. Bourgeau, J. Demerjian, and H. Chaouchi, "Extended privacy in crowdsourced location-based services using mobile cloud computing," Mobile Information Systems, vol. 2016, Article ID 7867206, 13 pages, 2016.

[15] X. Jin, Z. Wang, and W. Hua, "Cooperative runtime offloading decision algorithm for mobile cloud computing," Mobile Information Systems, vol. 2019, Article ID 8049804, 17 pages, 2019.

[16] E. Park and K. J. Kim, “An integrated adoption model of mobile cloud services: exploration of key determinants and extension of Technology Acceptance Model," Telematics and Informatics, vol. 31, no. 3, pp. 376-385, 2014.

[17] S.-H. Kim and J. K. Kim, "Determinants of the adoption of mobile cloud computing services," Information Development, vol. 34, no. 1, pp. 44-63, 2018.

[18] Y. Karaca, M. Moonis, Y.-D. Zhang, and C. Gezgez, "Mobile cloud computing based stroke healthcare system," International Journal of Information Management, vol. 45, pp. 250-261, 2019.

[19] R. U. Amin, I. Inayat, B. Shahzad, K. Saleem, and L. Aijun, "An empirical study on acceptance of secure healthcare service in Malaysia, Pakistan, and Saudi Arabia: a mobile cloud computing perspective," Annals of Telecommunications, vol. 72, no. 5-6, pp. 253-264, 2017.

[20] Z. Mitrovic, N. Klaas, and F. Mbhele, "Benefits of introducing the cloud computing based m-government in the western cape: policy implications," in Proceedings of the 7th International Conference on Theory and Practice of Electronic Governance, pp. 317-325, Association for Computing Machinery, Seoul, Republic of Korea, October 2013.

[21] K. Simić, J. Dadić, L. Paunović, M. Milutinović, and Z. Bogdanović, "Delivering mobile government services through cloud computing," Innovative Issues and Approaches in Social Sciences, vol. 5, no. 2, pp. 150-160, 2012.
[22] M. Ntaliani, C. Costopoulou, and S. Karetsos, "Mobile government: a challenge for agriculture," Government Information Quarterly, vol. 25, no. 4, pp. 699-716, 2008.

[23] Q. Kharma, N. M. Turab, Q. Shambour, and M. Hassan, "Secure cloud-mediator architecture for mobile-government using RBAC and DUKPT," International Journal of Interactive Mobile Technologies, vol. 14, no. 4, pp. 44-60, 2020.

[24] Y.-H. Kim, I.-K. Lim, S.-G. Kang, and J.-K. Lee, Mobile Cloud E-Gov Design and Implementation Using WebSockets API, pp. 204-211, Springer Berlin Heidelberg, Berlin, Germany, 2011.

[25] A. A. Z. A. Ibrahim, M. U. Wasim, S. Varrette, and P. Bouvry, "Presence: monitoring and modelling the performance metrics of mobile cloud SaaS web services," Mobile Information Systems, vol. 2018, Article ID 1351386, 14 pages, 2018.

[26] S.-H. Chang and Z.-R. Chen, "Protecting mobile crowd sensing against sybil attacks using cloud based trust management system," Mobile Information Systems, vol. 2016, Article ID 6506341, 10 pages, 2016.

[27] M. A. Almaiah and A. Al-Khasawneh, "Investigating the main determinants of mobile cloud computing adoption in university campus," Education and Information Technologies, vol. 25, no. 4, pp. 3087-3107, 2020.

[28] H. Carreiro and T. Oliveira, "Impact of transformational leadership on the diffusion of innovation in firms: application to mobile cloud computing," Computers in Industry, vol. 107, pp. 104-113, 2019.

[29] M. R. Rahimi, J. Ren, C. H. Liu, A. V. Vasilakos, and N. Venkatasubramanian, "Mobile cloud computing: a survey, state of art and future directions," Mobile Networks and Applications, vol. 19, no. 2, pp. 133-143, 2014.

[30] F. H. Abdulfattah, "Factors affecting students' intention toward mobile cloud computing," International Journal of Cloud Applications and Computing, vol. 9, no. 2, pp. 28-42, 2019.

[31] Y. Liang, G. Qi, X. Zhang, and G. Li, "The effects of e-Government cloud assimilation on public value creation: an empirical study of China," Government Information Quarterly, vol. 36, no. 4, Article ID 101397, 2019.

[32] I. Arpaci, Y. Cetin Yardimci, S. Ozkan, and O. Turetken, "Organizational adoption of information technologies: a literature review," International Journal of eBusiness and eGovernment Studies, vol. 4, pp. 37-50, 2012.

[33] L. G. Tornatzky and M. Fleischer, The Processes of Technological Innovation, Lexington Books, Lanham, MD, USA, 1990.

[34] H.-J. Wang and J. Lo, "Adoption of open government data among government agencies," Government Information Quarterly, vol. 33, no. 1, pp. 80-88, 2016.

[35] I. Arpaci, "A qualitative study on the adoption of bring your own device (BYOD) practice," International Journal of E-Adoption, vol. 7, no. 2, pp. 1-14, 2015.

[36] T. Oliveira, M. Thomas, and M. Espadanal, "Assessing the determinants of cloud computing adoption: an analysis of the manufacturing and services sectors," Information \& Management, vol. 51, no. 5, pp. 497-510, 2014.

[37] R. Martins, T. Oliveira, and M. A. Thomas, "An empirical analysis to assess the determinants of SaaS diffusion in firms," Computers in Human Behavior, vol. 62, pp. 19-33, 2016.

[38] P.-F. Hsu, S. Ray, and Y.-Y. Li-Hsieh, "Examining cloud computing adoption intention, pricing mechanism, and deployment model," International Journal of Information Management, vol. 34, no. 4, pp. 474-488, 2014. 
[39] M. Li, D. Zhao, and Y. Yu, "TOE drivers for cloud transformation: direct or trust-mediated?" Asia Pacific Journal of Marketing and Logistics, vol. 27, no. 2, pp. 226-248, 2015.

[40] Z. Yang, J. Sun, Y. Zhang, and Y. Wang, "Understanding SaaS adoption from the perspective of organizational users: a tripod readiness model," Computers in Human Behavior, vol. 45, pp. 254-264, 2015.

[41] I.-C. Chang, H.-G. Hwang, M.-C. Hung, M.-H. Lin, and D. C. Yen, "Factors affecting the adoption of electronic signature: executives' perspective of hospital information department," Decision Support Systems, vol. 44, no. 1, pp. 350-359, 2007.

[42] N. A. Ahmad, S. M. Drus, and H. Kasim, "Factors that influence the adoption of enterprise architecture by public sector organizations: an empirical study," IEEE Access, vol. 8, pp. 98847-98873, 2020.

[43] F. Herzberg, "One more time: how do you motivate employees?” Harvard Business Review, vol. 65, no. 5, pp. 109120, 1987.

[44] R. T. Cenfetelli and A. Schwarz, "Identifying and testing the inhibitors of technology usage intentions," Information Systems Research, vol. 22, no. 4, pp. 808-823, 2011.

[45] S.-G. Lee, S. H. Chae, and K. M. Cho, "Drivers and inhibitors of SaaS adoption in Korea," International Journal of Information Management, vol. 33, no. 3, pp. 429-440, 2013.

[46] S. C. Park and S. Y. Ryoo, "An empirical investigation of endusers' switching toward cloud computing: a two factor theory perspective," Computers in Human Behavior, vol. 29, no. 1, pp. 160-170, 2013.

[47] S. Asadi, R. Abdullah, M. Safaei, and S. Nazir, "An integrated SEM-Neural network approach for predicting determinants of adoption of wearable healthcare devices," Mobile Information Systems, vol. 2019, Article ID 8026042, 9 pages, 2019.

[48] D. Gu, S. Khan, I. U. Khan, and S. U. Khan, "Understanding mobile tourism shopping in Pakistan: an integrating framework of innovation diffusion theory and technology acceptance model," Mobile Information Systems, vol. 2019, Article ID 1490617, 18 pages, 2019.

[49] E. Miranda Bojórquez, O. O. Vergara Villegas, V. G. Cruz Sánchez, J. L. García-Alcaraz, and J. Favela Vara, "Study on mobile augmented reality adoption for Mayo language learning," Mobile Information Systems, vol. 2016, Article ID 1069581, 15 pages, 2016.

[50] S. Gao, J. Krogstie, and K. Siau, "Adoption of mobile information services: an empirical study," Mobile Information Systems, vol. 10, no. 2, pp. 147-171, 2014.

[51] F. D. Davis, "Perceived usefulness, perceived ease of use, and user acceptance of information technology," MIS Quarterly, vol. 13, no. 3, pp. 319-340, 1989.

[52] V. Venkatesh, M. G. Morris, G. B. Davis, and F. D. Davis, "User acceptance of information technology: toward a unified view," MIS Quarterly, vol. 27, no. 3, pp. 425-478, 2003.

[53] E. M. Rogers, Diffusion of Innovations, Simon \& Schuster, New York, NY, USA, 4th edition, 2020.

[54] D. Zheng, J. Chen, L. Huang, and C. Zhang, "E-government adoption in public administration organizations: integrating institutional theory perspective and resource-based view," European Journal of Information Systems, vol. 22, no. 2, pp. 221-234, 2013.

[55] W. W. Powell and P. J. Dimaggio, The New Institutionalism in Organizational Analysis, University of Chicago Press, Chicago, IL, USA, 1991.
[56] K. Alzadjali and A. Elbanna, "Smart institutional intervention in the adoption of digital infrastructure: the case of government cloud computing in Oman," Information Systems Frontiers, vol. 22, no. 2, pp. 365-380, 2020.

[57] J. Lansing and A. Sunyaev, "Trust in cloud computing," ACM sigmis database: The database for advances in Information Systems, vol. 47, no. 2, pp. 58-96, 2016.

[58] D. H. McKnight, L. L. Cummings, and N. L. Chervany, "Initial trust formation in new organizational relationships," Academy of Management Review, vol. 23, no. 3, pp. 473-490, 1998.

[59] D. H. McKnight, V. Choudhury, and C. Kacmar, "Developing and validating trust measures for e-Commerce: an integrative typology," Information Systems Research, vol. 13, no. 3, pp. 334-359, 2002.

[60] D. H. Mcknight, M. Carter, J. B. Thatcher, and P. F. Clay, "Trust in a specific technology," ACM Transactions on Management Information Systems, vol. 2, no. 2, pp. 1-25, 2011.

[61] A. Vance, C. Elie-Dit-Cosaque, and D. W. Straub, "Examining trust in information technology artifacts: the effects of system quality and culture," Journal of Management Information Systems, vol. 24, no. 4, pp. 73-100, 2008.

[62] T. Oliveira, M. Faria, M. A. Thomas, and A. Popovič, "Extending the understanding of mobile banking adoption: when UTAUT meets TTF and ITM," International Journal of Information Management, vol. 34, no. 5, pp. 689-703, 2014.

[63] T. Heart, "Who is out there?: exploring the effects of trust and perceived risk on saas adoption intentions," $A C M$ SIGMIS Database: The DATABASE for Advances in Information Systems, vol. 41, no. 3, pp. 49-68, 2010.

[64] I. Arpaci, Y. Yardimci Cetin, and O. Turetken, "A crosscultural analysis of smartphone adoption by Canadian and Turkish organizations," Journal of Global Information Technology Management, vol. 18, no. 3, pp. 214-238, 2015.

[65] Y. Liang, G. Qi, K. Wei, and J. Chen, "Exploring the determinant and influence mechanism of e-Government cloud adoption in government agencies in China," Government Information Quarterly, vol. 34, no. 3, pp. 481-495, 2017.

[66] P. Gupta, A. Seetharaman, and J. R. Raj, "The usage and adoption of cloud computing by small and medium businesses," International Journal of Information Management, vol. 33, no. 5, pp. 861-874, 2013.

[67] V. S. Narwane, B. E. Narkhede, R. D. Raut, B. B. Gardas, P. Priyadarshinee, and M. S. Kavre, "To identify the determinants of the CloudIoT technologies adoption in the Indian MSMEs: structural equation modelling approach," International Journal of Business Information Systems, vol. 31, no. 3, pp. 322-353, 2019.

[68] E. B. Swanson, "Information systems innovation among organizations," Management Science, vol. 40, no. 9, pp. 1069-1092, 1994.

[69] İ. Arpaci, "E-government and technological innovation in Turkey," Transforming Government: People, Process and Policy, vol. 4, no. 1, pp. 37-53, 2010.

[70] D.-H. Shin, "User centric cloud service model in public sectors: policy implications of cloud services," Government Information Quarterly, vol. 30, no. 2, pp. 194-203, 2013.

[71] Y. Liang, G. Zhang, F. Xu, and Y. Wang, "User acceptance of internet of vehicles services: empirical findings of partial least square structural equation modeling (PLS-SEM) and fuzzy sets qualitative comparative analysis (fsQCA)," Mobile Information Systems, vol. 2020, Article ID 6630906, 22 pages, 2020 . 
[72] S. Paquette, P. T. Jaeger, and S. C. Wilson, "Identifying the security risks associated with governmental use of cloud computing," Government Information Quarterly, vol. 27, no. 3, pp. 245-253, 2010.

[73] D. Zissis and D. Lekkas, "Securing e-Government and e-Voting with an open cloud computing architecture," Government Information Quarterly, vol. 28, no. 2, pp. 239251, 2011.

[74] L. Deng, Y. Li, L. Yao, Y. Jin, and J. Gu, "Power-aware resource reconfiguration using genetic algorithm in cloud computing," Mobile Information Systems, vol. 2016, Article ID 4859862, 9 pages, 2016.

[75] J. Repschlaeger, K. Erek, and R. Zarnekow, "Cloud computing adoption: an empirical study of customer preferences among start-up companies," Electronic Markets, vol. 23, no. 2, pp. 115-148, 2013.

[76] R. Bose and X. Luo, "Integrative framework for assessing firms' potential to undertake Green IT initiatives via virtualization-a theoretical perspective," The Journal of Strategic Information Systems, vol. 20, no. 1, pp. 38-54, 2011.

[77] D. C. Hambrick and P. A. Mason, "Upper echelons: the organization as a reflection of its top managers," Academy of Management Review, vol. 9, no. 2, pp. 193-206, 1984.

[78] F. Mohammed, O. Ibrahim, M. Nilashi, and E. Alzurqa, "Cloud computing adoption model for e-government implementation," Information Development, vol. 33, no. 3, pp. 303-323, 2017.

[79] G. H. M. Oliveira and E. W. Welch, "Social media use in local government: linkage of technology, task, and organizational context," Government Information Quarterly, vol. 30, no. 4, pp. 397-405, 2013.

[80] N. Urbach and A. Frederik, "Structural equation modeling in information systems research using partial least squares," Journal of Information Technology Theory and Application, vol. 11, no. 2, pp. 5-40, 2010.

[81] R. W. Brislin, "Back-translation for cross-cultural research," Journal of Cross-Cultural Psychology, vol. 1, no. 3, pp. 185216, 1970.

[82] J. Wu, F. Ding, M. Xu, Z. Mo, and A. Jin, "Investigating the determinants of decision-making on adoption of public cloud computing in e-government," Journal of Global Information Management, vol. 24, no. 3, pp. 71-89, 2016.

[83] H. Yang, H. Lee, and H. Zo, "User acceptance of smart home services: an extension of the theory of planned behavior," Industrial Management \& Data Systems, vol. 117, no. 1, pp. 68-89, 2017.

[84] J. F. Hair, C. M. Ringle, and M. Sarstedt, "PLS-SEM: indeed a silver bullet," Journal of Marketing Theory and Practice, vol. 19, no. 2, pp. 139-152, 2011.

[85] J. F. Hair, J. J. Risher, M. Sarstedt, and C. M. Ringle, "When to use and how to report the results of PLS-SEM," European Business Review, vol. 31, no. 1, pp. 2-24, 2019.

[86] P. R. Palos-Sanchez, J. R. Saura, and F. Debasa, "The influence of social networks on the development of recruitment actions that favor user interface design and conversions in mobile applications powered by linked data," Mobile Information Systems, vol. 2018, Article ID 5047017, 11 pages, 2018.

[87] J. Benitez, J. Henseler, A. Castillo, and F. Schuberth, "How to perform and report an impactful analysis using partial least squares: guidelines for confirmatory and explanatory IS research," Information \& Management, vol. 57, no. 2, Article ID 103168, 2020.
[88] J. F. Hair, G. T. M. Hult, C. M. Ringle, and M. Sarstedt, $A$ Primer on Partial Least Squares Structural Equation Modeling (PLS-SEM), SAGE, New York, NY, USA, 2nd edition, 2017.

[89] E. M. Ghazali, D. S. Mutum, and M. Y. Woon, "Multiple sequential mediation in an extended uses and gratifications model of augmented reality game Pokémon Go," Internet Research, vol. 29, no. 3, pp. 504-528, 2019.

[90] C. Fornell and D. F. Larcker, "Evaluating structural equation models with unobservable variables and measurement Error," Journal of Marketing Research, vol. 18, no. 1, pp. 39-50, 1981.

[91] M. Stone, "Cross-validatory choice and assessment of statistical predictions," Journal of the Royal Statistical Society: Series B (Methodological), vol. 36, no. 2, pp. 111-133, 1974.

[92] S. Geisser, "A predictive approach to the random effect model," Biometrika, vol. 61, no. 1, pp. 101-107, 1974.

[93] J. Henseler and M. Sarstedt, "Goodness-of-fit indices for partial least squares path modeling," Computational Statistics, vol. 28, no. 2, pp. 565-580, 2013.

[94] P. Mikalef, J. Krogstie, I. O. Pappas, and P. Pavlou, "Exploring the relationship between big data analytics capability and competitive performance: the mediating roles of dynamic and operational capabilities," Information \& Management, vol. 57, no. 2, Article ID 103169, 2020.

[95] R. M. Baron and D. A. Kenny, "The moderator-mediator variable distinction in social psychological research: conceptual, strategic, and statistical considerations," Journal of Personality and Social Psychology, vol. 51, no. 6, pp. 11731182, 1986.

[96] M. E. Sobel, “Asymptotic confidence intervals for indirect effects in structural equation models," Sociological Methodology, vol. 13, pp. 290-312, 1982.

[97] I. Arpaci, Ş Kesici, and M. Baloğlu, "Individualism and internet addiction: the mediating role of psychological needs," Internet Research, vol. 28, no. 2, pp. 293-314, 2018.

[98] K. J. Preacher and A. F. Hayes, "Asymptotic and resampling strategies for assessing and comparing indirect effects in multiple mediator models," Behavior Research Methods, vol. 40, no. 3, pp. 879-891, 2008.

[99] C. Nitzl, J. L. Roldan, and G. Cepeda, "Mediation analysis in partial least squares path modeling," Industrial Management \& Data Systems, vol. 116, no. 9, pp. 1849-1864, 2016.

[100] A. F. Hayes, Introduction to Mediation, Moderation, and Conditional Process Analysis: A Regression-Based Approach, Guilford Publications, New York, NY, USA, 2017.

[101] O. Ali, J. Soar, and J. Yong, "An investigation of the challenges and issues influencing the adoption of cloud computing in Australian regional municipal governments," Journal of Information Security and Applications, vol. 27-28, pp. 19-34, 2016.

[102] L. Li, K. Du, S. Xin, and W. Zhang, "Creating value through IT-enabled integration in public organizations: a case study of a prefectural chinese center for disease control and prevention," International Journal of Information Management, vol. 37, no. 1, pp. 1575-1580, 2017.

[103] W. Zhang, O. Gutierrez, and K. Mathieson, "Information systems research in the nonprofit context: challenges and opportunities," Communications of the Association for Information Systems, vol. 12, pp. 1-12, 2010.

[104] T. Hess, "Opportunities and risks of software-as-a-service: findings from a survey of IT executives," Decision Support Systems, vol. 52, no. 1, pp. 232-246, 2011. 
[105] L. Lapointe and S. Rivard, "A multilevel model of resistance to information technology implementation," MIS Quarterly, vol. 29, no. 3, pp. 461-491, 2005.

[106] S. Rivard and L. Lapointe, "Information technology implementers' responses to user resistance: nature and effects," MIS Quarterly, vol. 36, no. 3, pp. 897-920, 2012. 